\title{
Multi-touch cobalt phosphide-tungsten phosphide heterojunctions anchored on reduced graphene oxide boosting wide $\mathrm{pH}$ hydrogen evolution
}

\author{
Yanqing Jiao ${ }^{1}$, Haijing Yan ${ }^{1}$, Dongxu Wang ${ }^{1}$, Xiuwen Wang ${ }^{2}$, Siwei Xu${ }^{1}$, Ying Xie ${ }^{1}$, Aiping Wu ${ }^{1}$, Li Jiang ${ }^{1}$, \\ Chungui Tian ${ }^{1 *}$, Ruihong Wang ${ }^{1}$ and Honggang $\mathrm{Fu}^{1 *}$
}

\begin{abstract}
Multi-interface engineering is deemed as an effective strategy to boost catalytic activity via electronic structure modulation. However, it is still a big challenge due to the phase-separation tendency. Herein, we designed CoP-WP heterojunctions with multi-touch interfaces using $\mathrm{Co}_{8} \mathrm{~W}_{18}$, a definite structure polyoxometalate-based polynuclear cobalt molecular cluster, as a precursor. The CoP-WP heterojunctions anchored on reduced graphene oxide (CoP-WP/rGO) were obtained by growing $\mathrm{Co}_{8} \mathrm{~W}_{18}$ on $\mathrm{GO}$ followed by phosphorization. The intrinsic $\{\mathrm{Co}-\mathrm{O}-\mathrm{W}\}$ coordination modes in $\mathrm{Co}_{8} \mathrm{~W}_{18}$ are conducive to the formation of the multiple interfaces between CoP and WP. The abundant intimate interfaces in CoP-WP heterojunctions promote the electron transfer from WP to CoP, thus regulating the interfacial electronic structure and optimizing the hydrogen adsorption free energy $\left(\Delta G_{H^{*}}\right)$, as verified by $\mathrm{X}$-ray photoelectron spectroscopy analysis and theoretical calculations. Furthermore, the integration of rGO provides CoP-WP/rGO with a large surface area and high conductivity, aiding mass transport and charge transfer. CoP-WP/rGO exhibits remarkable hydrogen evolution reaction (HER) activity with low overpotentials of 96, 130,

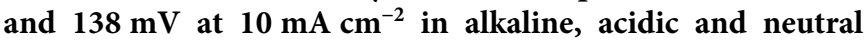
media, respectively, and has long-term durability. Our discovery provides an opportunity to design heterojunction materials with multi-coupled interfaces at low-cost and efficient HER catalysts.
\end{abstract}

Keywords: heterojunction, modulating electronic structure, electrocatalytic hydrogen evolution, metal phosphides, polyoxometalates

\section{INTRODUCTION \\ The excessive consumption of fossil fuels inevitably causes ser- ious environmental problems. $\mathrm{H}_{2}$, a clean energy carrier with the characteristic of high energy density, holds a bright promise to realize the green development of the whole society. Electro- catalytic hydrogen evolution reaction (HER) via water splitting is an environment-friendly and high-efficient strategy to pro- duce high-purity hydrogen, driven by low-voltage electricity from photovoltaic power [1-3]. Currently, not more than $4 \%$ hydrogen is produced by electrolysis, partly because the sluggish}

kinetics of HER requires efficient catalysts to catalyze [4]. Now, the most efficient HER electrocatalysts are still platinum-based materials. The prohibitive cost and scarcity of Pt are a strong driving force to search for cost-effective alternatives. Moreover, the HER process varies with $\mathrm{pH}$ values. Generally, the active performance in alkaline and neutral conditions could not reach that in acid electrolyte $[5,6]$. Therefore, the development of nonnoble-metal materials that can be operated with high performance irrespective of $\mathrm{pH}$ value is pursued.

To optimize the catalytic activity, two focus points are increasing the number of active sites and improving the intrinsic catalytic activity $[7,8]$. In this regard, constructing heterostructure interfaces is an effective strategy for realizing the simultaneous modulations of the aforementioned aspects [9-11]. Heterojunctions constructed by early (W, Mo, V, etc.) and late transition metals $(\mathrm{TM}=\mathrm{Co}, \mathrm{Ni}, \mathrm{Fe}$, etc.) show an unusual catalytic activity due to interfacial electron redistribution based on the "d electron complementary effect" [12-14]. For instance, $\mathrm{Ni}_{3} \mathrm{~N}-\mathrm{VN} / \mathrm{NF}$ interstitial compound heterojunction exhibits an elevated HER performance due to the heterointerfaces for easy adsorption/activation of the intermediates [15]. On the other hand, tungsten/molybdenum-based phosphides with analogous Pt electronic structure, relatively high conductivity, and mechanical strength are emerging catalysts, where high electronegative $\mathrm{P}$ serves as a "proton trap" and $\mathrm{Mo} / \mathrm{W}$ works as a "hydride acceptor" during the catalytic process [16]. However, single-metal phosphides (such as WP and MoP) often have low activity due to the strong electron-donating characteristic of $\mathrm{Mo} / \mathrm{W}$. Integrating foreign metals has been widely explored to modulate electronic structures and accelerate the hydrogen evolution kinetics $[17,18]$. For example, Lan's group [19] prepared a CoP/MoP@NC/CC heterojunction with excellent catalytic activity $\left(\eta_{10}=94 \mathrm{mV}\right)$, owing to the synergistic effect of CoP and MoP. In the case of $\mathrm{W}$, it is challenging to construct analogous heterojunctions due to the phase-separation tendency [20]. Conventional strategies to build the Co-W-based heterojunctions can be summarized as follows: one is based on $\mathrm{CoWO}_{4}$ precursor [21]; the second is the stepwise introduction of Co and W sources [22]; the third one selects CoW-based metal-organic framework as a precursor [23]. However, these strategies only produce limited heterointerfaces that are coupled loosely. Therefore, it is hard to realize a Co-W-based heterostructure

\footnotetext{
${ }^{1}$ Key Laboratory of Functional Inorganic Material Chemistry, Ministry of Education, Heilongjiang University, Harbin 150080, China

${ }^{2}$ Heilongjiang Provincial Key Laboratory of Surface Active Agent and Auxiliary, Qiqihar University, Qiqihar 161006, China

* Corresponding authors (emails: tianchungui@hlju.edu.cn (Tian C); fuhg@vip.sina.com or fuhg@hlju.edu.cn (Fu H))
} 
with a high degree of integration and rich interfaces in one step.

Polyoxometalates (POMs) with nano sizes, high negative charges, adjustable composition, and oxygen-rich surface capable of strong coordination, have been widely utilized as transferable building blocks to target functional materials [24-26]. POMs containing $\mathrm{TM}(\mathrm{TM}=\mathrm{Co}, \mathrm{Ni}, \mathrm{Fe}$, etc.) provide the flexibility to fabricate multi-interfacial hybrid nanomaterials since there exist abundant intramolecular interfaces due to the inherent $\{\mathrm{TM}-\mathrm{O}-\mathrm{W} / \mathrm{Mo}\}$ coordination modes [26,27]. Considering the ratio of TM to W/Mo atoms could be controlled beforehand at a molecular level, we speculate that the precise ratio control may be achieved in the electrocatalysts. In this context, a POM-based polynuclear cobalt cluster $\mathrm{K}_{8} \mathrm{Na}_{8}[(\mathrm{~A}-\alpha-$ $\left.\left.\mathrm{SiW}_{9} \mathrm{O}_{34}\right)_{2} \mathrm{Co}_{8}(\mathrm{OH})_{6}\left(\mathrm{H}_{2} \mathrm{O}\right)_{2}\left(\mathrm{CO}_{3}\right)_{3}\right] \cdot 52 \mathrm{H}_{2} \mathrm{O}$ (aliased as $\mathrm{Co}_{8} \mathrm{~W}_{18}$, Fig. S1) captures our attention [28,29]. The assembly-immobilization strategy is preferred, considering it is useful that smallsized $\mathrm{Mo} / \mathrm{W}$-based catalysts on reduced graphene oxide (rGO) were synthesized by this method [30-32]. Herein, a unique CoPWP heterostructure anchored on rGO (denoted as CoP-WP/ rGO) was created through hydrothermal reaction and subsequently controlled phosphorization using $\mathrm{Co}_{8} \mathrm{~W}_{18}$ precursor. The ratio of Co to $\mathrm{W}$ atoms in CoP-WP/rGO is inherited from $\mathrm{Co}_{8} \mathrm{~W}_{18}$. As expected, great interfaces are formed in CoP-WP/ $\mathrm{rGO}$, where the interfacial electron redistribution occurs, optimizing the hydrogen adsorption energy. As a result, CoP-WP/ rGO can effectively drive the HER over a wide $\mathrm{pH}$ range. The required overpotentials to reach $10 \mathrm{~mA} \mathrm{~cm}^{-2}$ are 96,130 , and $138 \mathrm{mV}$ in $1 \mathrm{~mol} \mathrm{~L}^{-1} \mathrm{KOH}, 0.5 \mathrm{~mol} \mathrm{~L}^{-1} \mathrm{H}_{2} \mathrm{SO}_{4}$, and $1 \mathrm{~mol} \mathrm{~L}^{-1}$ phosphate buffer saline (PBS), respectively, outperforming the corresponding single-component samples. The excellent activity benefits from the synergistic effect of heterostructure between $\mathrm{CoP}$ and WP, and the enhanced electronic conductivity originated from the incorporation with rGO. This work seeks to construct heterojunctions with firm contact interfaces for targeting renewable energy electrocatalysis.

\section{EXPERIMENTAL SECTION}

\section{Synthesis of CoP-WP/rGO}

The fresh GO dispersion $\left(20 \mathrm{~mL}, 4 \mathrm{mg} \mathrm{mL}^{-1}\right)$ reacted with $20 \mathrm{~mL}$ of $4 \mathrm{mg} \mathrm{mL}^{-1}$ polyethyleneimine (PEI) aqueous solution, under stirring for $24 \mathrm{~h}$. After centrifugal separation, the obtained PEI-GO was dispersed in deionized water to form $40 \mathrm{~mL}$ $2 \mathrm{mg} \mathrm{mL}^{-1}$ PEI-GO solution. Next, $\mathrm{Co}_{8} \mathrm{~W}_{18} \quad(120 \mathrm{mg})$ in $\mathrm{CH}_{3} \mathrm{COONa}$ solution $\left(30 \mathrm{~mL}, 0.5 \mathrm{~mol} \mathrm{~L}^{-1}\right.$ ) was added dropwise into the PEI-GO solution under vigorous stirring. After $24 \mathrm{~h}$, the mixture was transferred into a $100-\mathrm{mL}$ Teflon-lined autoclave, followed by heating at $160^{\circ} \mathrm{C}$ for $18 \mathrm{~h}$. During the hydrothermal treatment, the GO was partially reduced to rGO. After cooling down to room temperature, the as-prepared precipitate $\left(\mathrm{Co}_{8} \mathrm{~W}_{18} / \mathrm{rGO}\right)$ was centrifuged and washed with deionized water and ethanol several times, then dried at $60^{\circ} \mathrm{C}$ overnight. After that, the $\mathrm{Co}_{8} \mathrm{~W}_{18} / \mathrm{rGO}$ powder was first calcined from ambient temperature to $320^{\circ} \mathrm{C}$ and then maintained for $6 \mathrm{~h}$. Subsequently, the as-obtained sample $(100 \mathrm{mg})$ and $\mathrm{NaH}_{2} \mathrm{PO}_{2}(1 \mathrm{~g})$ were put into two single porcelain boats, respectively. The porcelain boat loaded with $\mathrm{NaH}_{2} \mathrm{PO}_{2}$ was placed at the upstream side of the quartz tube at a distance of about $5 \mathrm{~cm}$ from the other one. Then, the quartz tube was calcinated at $800^{\circ} \mathrm{C}$ for $3 \mathrm{~h}$ with a ramping rate of $5^{\circ} \mathrm{C} \mathrm{min}{ }^{-1}$ in an inert $\mathrm{N}_{2}$ atmosphere. After natural cooling, the targeted sample (CoP-WP/rGO) was obtained.

A series of control samples were synthesized by either changing the phosphating temperature or tuning the concentration of the starting reactant $\mathrm{Co}_{8} \mathrm{~W}_{18}$ to investigate the influence of calcination temperature and $\mathrm{Co}_{8} \mathrm{~W}_{18}$ amount on the catalytic activity. The CoP-WP/rGO-700 and CoP-WP/rGO-900 were obtained under the same conditions, except that the phosphating temperature was changed to 700 and $900^{\circ} \mathrm{C}$, respectively. Similar to the above, when the reactant amount of $\mathrm{Co}_{8} \mathrm{~W}_{18}$ was 80 and $160 \mathrm{mg}$ (the mass ratios of $\mathrm{Co}_{8} \mathrm{~W}_{18}$ and GO were 1 and 2), the final products calcinated at $800^{\circ} \mathrm{C}$ were designated as CoP-WP/ rGO-1 and CoP-WP/rGO-2.

\section{Synthesis of WP/rGO}

The synthetic procedure is very similar to that for CoP-WP/ rGO, except that $\mathrm{H}_{4}\left[\mathrm{SiO}_{4}\left(\mathrm{~W}_{3} \mathrm{O}_{9}\right)_{4}\right]\left(\mathrm{SiW}_{12}\right)$ was used in place of $\mathrm{Co}_{8} \mathrm{~W}_{18}$.

\section{Synthesis of CoP/rGo}

The synthetic procedure is the same as that for CoP-WP/rGO, except that $\mathrm{CoSO}_{4} \cdot 7 \mathrm{H}_{2} \mathrm{O}$ was used instead of $\mathrm{Co}_{8} \mathrm{~W}_{18}$.

\section{Synthesis of CoP-WP nanoparticles (NPs)}

The obtained $\mathrm{Co}_{8} \mathrm{~W}_{18}$ precursor was ground into powder and then calcined under the same condition for CoP-WP/rGO. Therefore, the as-obtained sample is denoted as CoP-WP NPs.

\section{Characterizations}

Powder X-ray diffraction (XRD) measurement was recorded on a Bruker D8 diffractometer using $\mathrm{Cu} \mathrm{Ka}(\lambda=1.5418 \AA)$ radiation with an acceleration voltage of $40 \mathrm{kV}$. Fourier transformed infrared (FT-IR) spectroscopy was performed using a PerkinElmer Spectrum. Thermogravimetric (TG) analysis was obtained on an SDT Q600 instrument with constant air flow. The Raman spectrum was recorded on a Raman spectrometer (JY, Labram HR 800). A scanning electron microscopy (SEM) test was conducted on a Hitachi S-4800 instrument at an accelerating voltage of $5 \mathrm{kV}$. Transmission electron microscopy (TEM) was carried out on a JEM-2100 at $200 \mathrm{kV}$ accelerating voltage. X-ray photoelectron spectroscopy (XPS) was measured on a VG ESCALAB MKII with $\mathrm{Mg} \mathrm{Ka}(1253.6 \mathrm{eV})$ achromatic X-ray radiation. The $\mathrm{N}_{2}$ adsorption-desorption isotherms of the samples were conducted using a Micromeritics Tristar II. Scanning Kelvin Probe (SKP) measurement (SKP5050 system, Scotland) was performed in an ambient atmosphere using a gold electrode as the reference electrode.

\section{Electrochemical measurements}

The electrochemical measurement was carried out using a conventional three-electrode system at ambient temperature connected to a CHI $760 \mathrm{E}$ electrochemical workstation. The working electrode was prepared by mixing $2.5 \mathrm{mg}$ of catalyst and $0.5 \mathrm{mg}$ of carbon black dispersed in $1 \mathrm{~mL}$ of water/ethanol $(v / v=$ 1:1). Then, $30 \mu \mathrm{L} 5 \mathrm{wt} \%$ Nafion solution was added to the mixture. The mixture was treated to obtain a dispersed slurry. The slurry was pasted on a piece of $\mathrm{Ni}$ foam current collector $(1.0 \mathrm{~cm} \times 1.0 \mathrm{~cm})$ for alkaline and neutral HER tests or carbon fiber paper (CFP, $1.0 \mathrm{~cm} \times 1.0 \mathrm{~cm}$ ) for acidic HER test and dried at $60^{\circ} \mathrm{C}$ overnight. A saturated calomel electrode was employed as the reference electrode in both acidic and neutral electrolytes, while a standard $\mathrm{Hg} / \mathrm{HgO}$ electrode as the reference electrode 
was selected under alkaline conditions. A graphite rod was used as the counter electrodes in all the electrochemical tests. After 20 cycles of cyclic voltammetry (CV) tests to stabilize the current, a linear sweep voltammogram (LSV) was conducted at a scan rate of $5 \mathrm{mV} \mathrm{s}^{-1}$. Electrochemical impedance spectroscopy (EIS) data were gathered in the frequency range of $0.01-100,000 \mathrm{~Hz}$. CV was tested at varied scan rates in the non-Faradaic potential range to calculate the electrochemical double-layer capacitance $\left(C_{\mathrm{dl}}\right)$. The long-term stability was evaluated by implementing 2000 cycles $\mathrm{CV}$ at $100 \mathrm{mV} \mathrm{s}^{-1}$ scan rate in the selected potential ranges. Moreover, the chronoamperometry current density-time $(i-t)$ curves were conducted under controlled potentials for $30 \mathrm{~h}$. All the potentials reported here were calibrated to a reversible hydrogen electrode (RHE) using the corresponding Nernst equation as suggested by the previous literature [15]. A $90 \% i R$ compensation was employed in all the electrochemical measurements. The overall water splitting measurement was carried out in a standard two-electrode system using $\mathrm{CoP}-\mathrm{WP} / \mathrm{rGO}$ as the cathode and $\mathrm{NiFe}$-layered double hydroxide/nickel foam $(\mathrm{LDH} / \mathrm{NF})$ as the anode in alkaline electrolyte.

\section{RESULTS AND DISCUSSION}

\section{Morphology and structure characterization}

The hybrid nanocatalyst CoP-WP/rGO was fabricated via several steps, as shown in Scheme 1. The hydrothermal method combined the as-synthesized POM $\mathrm{Co}_{8} \mathrm{~W}_{18}$ and GO based on our previously reported assembly-immobilization strategy [3032], forming the nanocomposite precursor $\mathrm{Co}_{8} \mathrm{~W}_{18} / \mathrm{rGO}$. Afterward, the as-synthesized $\mathrm{Co}_{8} \mathrm{~W}_{18} / \mathrm{rGO}$ was in-situ transformed to $\mathrm{CoP}-\mathrm{WP} / \mathrm{rGO}$ by air calcination and then phosphorized under an inert $\mathrm{N}_{2}$ atmosphere at $800^{\circ} \mathrm{C}$ for $3 \mathrm{~h}$. The POM-based polynuclear cobalt cluster $\mathrm{Co}_{8} \mathrm{~W}_{18}$ was selected as the precursor via deliberate design and consideration based on the following points. i. $\mathrm{Co}_{8} \mathrm{~W}_{18}$ contains two metal atoms, Co and W. They are in a determined ratio and are joined together in tight contact due to the $\{\mathrm{Co}-\mathrm{O}-\mathrm{W}\}$ coordination modes, guaranteeing efficient in-situ generation of CoP-WP interwoven heterostructure in a precise ratio. ii. The integrity of POM structure in an aqueous solution is key, to some extent. The POM structure is subject to the $\mathrm{pH}$ value, which sometimes decomposes into fragments or ions [33]. At this point, $\mathrm{Co}_{8} \mathrm{~W}_{18}$ is stable in an aqueous solution of about $9.0 \mathrm{pH}$ [29], ensuring its structural integrity during the assembly process with PEI-GO and supporting the proportion control reliability. iii. $\mathrm{Co}_{8} \mathrm{~W}_{18}$ species with high negative charges up to 16 can easily combine with PEI-GO with positive surface charges, enhancing the inhibition of agglomeration and coalescence. The GO served as a support and carbon source to realize the good dispersion and deoxygenation of $\mathrm{Co}_{8} \mathrm{~W}_{18}$ and enhance the conductivity of the corresponding materials. The PEI acted as a coupling agent to trap POM on GO, aside from nitrogen source for in-situ generation of $\mathrm{N}$-doped carbon. The structure and composition of $\mathrm{Co}_{8} \mathrm{~W}_{18}$ were investigated by XRD, FT-IR, and TG analysis (Figs S2, S3, and S4). Also, the IR test was used to identify the successful formation of $\mathrm{Co}_{8} \mathrm{~W}_{18} / \mathrm{rGO}$. As shown in Fig. S3, the characteristic peaks of the $\mathrm{Co}_{8} \mathrm{~W}_{18}$ polyanion are $1488,1383,985,936,887,860,803,680$, and $523 \mathrm{~cm}^{-1}$, which are in line with the literature $[28,29]$. They are retained in the assynthesized $\mathrm{Co}_{8} \mathrm{~W}_{18} / \mathrm{rGO}$ assembly. The characteristic absorption peak at $3428 \mathrm{~cm}^{-1}$ can be attributed to the vibration of $\mathrm{O}-\mathrm{H}$ $\left(v_{\text {as }}(\mathrm{O}-\mathrm{H})\right)$. The new peaks at 1646,1550 , and $1162 \mathrm{~cm}^{-1}$ associated with $v_{\mathrm{as}}(\mathrm{C}=\mathrm{O}), v_{\mathrm{as}}(\mathrm{C}=\mathrm{C})$, and $v_{\mathrm{as}}(\mathrm{C}-\mathrm{O}-\mathrm{N})$, respectively, are observed, which can be ascribed to PEI-GO, suggesting the formation of $\mathrm{Co}_{8} \mathrm{~W}_{18} / \mathrm{rGO}$. After pyrolysis of $\mathrm{Co}_{8} \mathrm{~W}_{18} / \mathrm{rGO}$ at $800^{\circ} \mathrm{C}, \mathrm{CoP}-\mathrm{WP} / \mathrm{rGO}$ was obtained. As shown in Fig. S3, the characteristic peaks of the $\mathrm{Co}_{8} \mathrm{~W}_{18}$ polyanion disappear, implying that $\mathrm{Co}_{8} \mathrm{~W}_{18}$ was somewhat converted to CoP-WP/rGO. According to the above results, CoP-WP/rGO contains many hydrophilic groups (hydroxyl and carboxylic groups), which are beneficial to the adsorption of reactant molecules and electrolyte penetration, promoting the surface reaction kinetics $[34,35]$.

$\mathrm{WP} / \mathrm{rGO}$ and CoP-WP NPs samples were also prepared for comparison. XRD was further performed to confirm the structures of the as-obtained catalysts. The XRD patterns (Fig. 1a and Fig. S5) of CoP-WP/rGO, WP/rGO, and CoP-WP NPs display intense and dominant diffraction peaks at $21.1^{\circ}, 28.7^{\circ}, 31.1^{\circ}$, $43.3^{\circ}, 44.7^{\circ}, 46.6^{\circ}$, and $56.8^{\circ}$, which match well with the $(101)$, (002), (011), (112), (211), (103), and (020) lattice planes of the orthorhombic WP (JCPDS No. 65-1484), respectively. In contrast, some other peaks are observed in the XRD patterns of

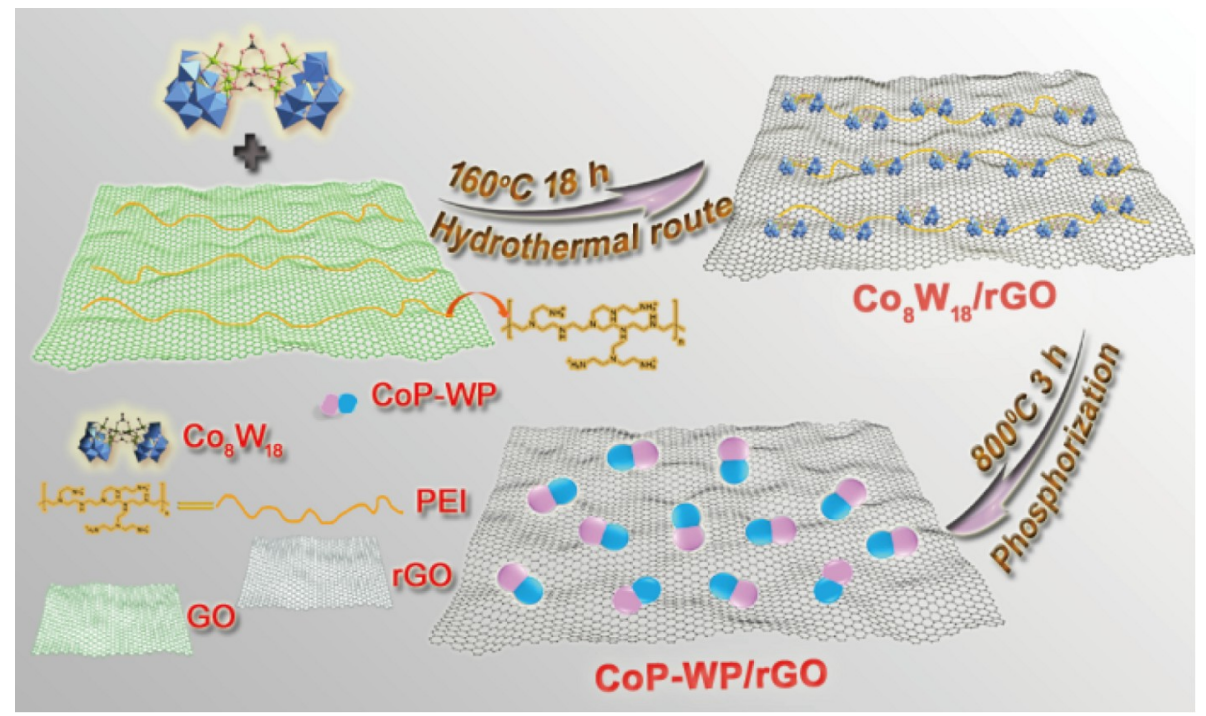

Scheme 1 Schematic illustration of the preparation of CoP-WP/rGO. 

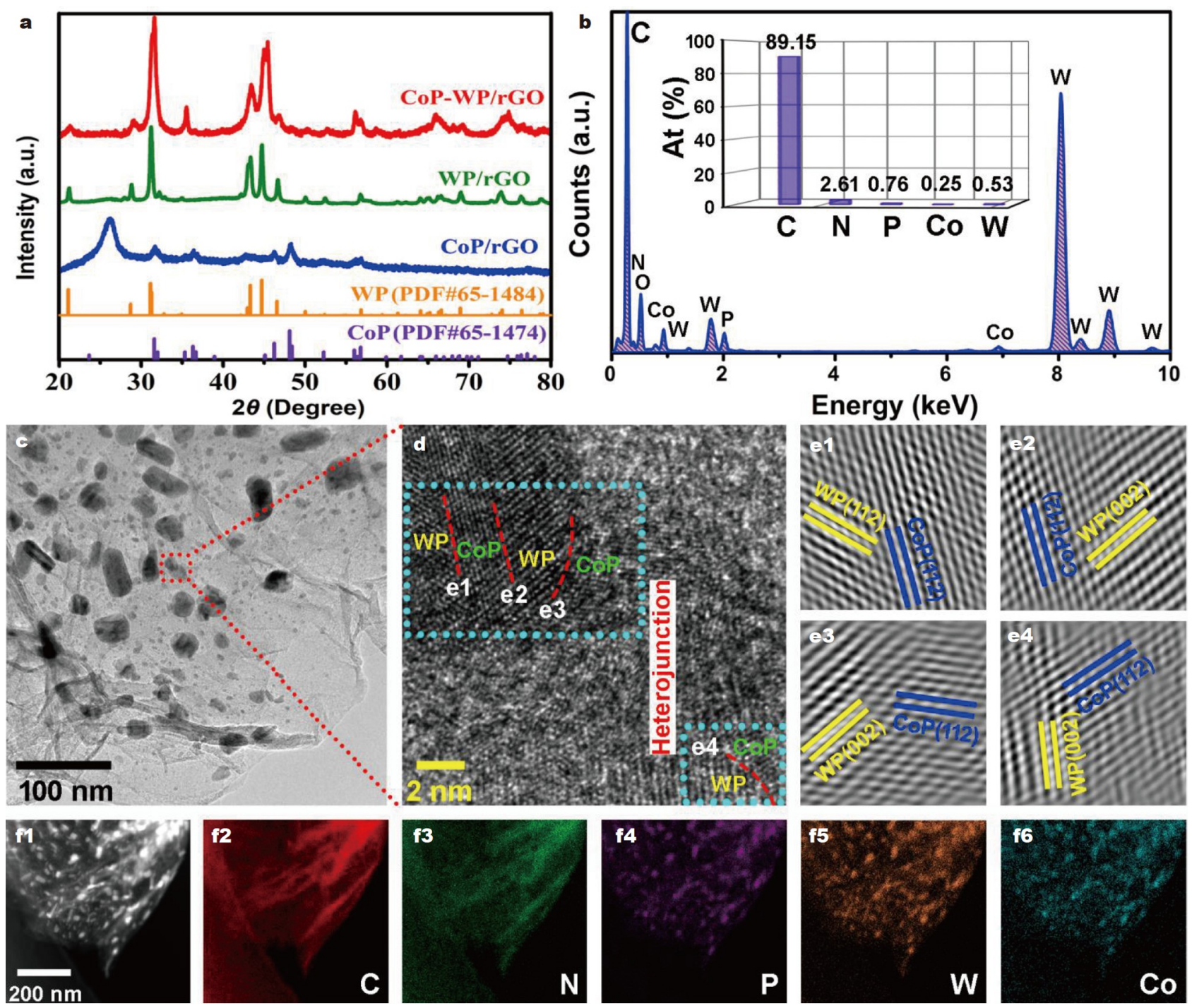

Figure 1 (a) XRD patterns of CoP-WP/rGO, WP/rGO and CoP/rGO, (b) EDS spectrum and the relative content in atomic percent in CoP-WP/rGO, (c) TEM image, (d) HRTEM image, (e) the IFFTs of the corresponding areas in (d), (f) scaning TEM image, and the corresponding elemental mapping images of $\mathrm{C}, \mathrm{N}, \mathrm{P}, \mathrm{W}$ and Co elements in CoP-WP/rGO.

CoP-WP/rGO, CoP/rGO, and CoP-WP NPs. The residual ones located at $31.6^{\circ}, 35.3^{\circ}, 45.1^{\circ}, 48.1^{\circ}$, and $56.0^{\circ}$ can be well-indexed to (011), (200), (210), (211), and (020) orthorhombic CoP (JCPDS No. 65-1474) reflections. A broad peak at about $26.2^{\circ}$ in $\mathrm{CoP} / \mathrm{rGO}$ can be assigned to the (002) facet of graphitic carbon because Co species has a highly catalytic ability for graphitization. Comparing the XRD patterns (Fig. 1a), we can conclude that both WP and $\mathrm{CoP}$ phases exist in $\mathrm{CoP}-\mathrm{WP} / \mathrm{rGO}$, suggesting the CoP-WP heterostructure formation. Besides, the peaks in the XRD pattern for CoP-WP/rGO appear wider than those for CoP-WP NPs, illustrating that immobilizing CoP-WP on the rGO layer strongly restricted the overgrowth of CoP-WP NPs. Raman spectroscopy was carried out to investigate the structural information of carbon materials. At around 1348 and $1583 \mathrm{~cm}^{-1}$, two distinct peaks are assigned to the D and G bands (Fig. S6). The intensity ratio of $\mathrm{D}$ and $\mathrm{G}$ bands $\left(I_{\mathrm{D}} / I_{\mathrm{G}}\right)$ reflects the disorder degree of graphite materials [32]. CoP-WP/rGO displays a higher $I_{\mathrm{D}} / I_{\mathrm{G}}$ value than $\mathrm{Co}_{8} \mathrm{~W}_{18} / \mathrm{rGO}$, illustrating that the phosphating process brings a particular increase of disorder degree, caused by the fact that nitrogen and phosphorus were inserted into the carbon framework during the high-temperature pyrolysis. In carbon materials, heteroatom doping ( $\mathrm{N}$ and $\mathrm{P}$, etc.) can tune the electron donor-acceptor behavior or spin density, regulating the hydrogen/hydroxyl adsorption energy, which is responsible for the elevated catalytic activity $[23,36]$. Moreover, the interaction between CoP-WP and rGO intensifies after phosphorization, conducive to charge transfer during the electrochemical reaction.

The morphology and microstructure of CoP-WP/rGO were investigated by SEM and TEM. As displayed in Fig. S7, CoP-WP heterostructure NPs with high uniformity are anchored and well-dispersed on the thin graphene layer. The SEM images of CoP-WP NPs and CoP-WP/rGO illustrate that rGO plays a crucial role in inhibiting the excessive aggregation of CoP-WP NPs, closely agreeing with the XRD results. The graphene layer shows no stacking due to the "space separator" role of CoP-WP NPs. X-ray energy-dispersive spectroscopy (EDS) analysis shows that the atomic ratio of $\mathrm{W}: \mathrm{Co}: \mathrm{P}: \mathrm{N}: \mathrm{C}$ is approximately 0.53:0.25:0.76:2.61:89.15 (Fig. 1b). The atomic ratio of $\mathrm{W}$ and Co measured at 2.12:1, is in good agreement with the ratio $(2.25: 1)$ 
in the $\mathrm{Co}_{8} \mathrm{~W}_{18}$ cluster. The atomic ratio of $\mathrm{W}$ and $\mathrm{Co}$ in CoP$\mathrm{WP} / \mathrm{rGO}$ is inherited from $\mathrm{Co}_{8} \mathrm{~W}_{18}$ POM, achieving accurate control. Fig. 1c and Fig. S8 show that CoP-WP NPs with different sizes are evenly distributed on the thin graphene layer. The size of the $\mathrm{Co}_{8} \mathrm{~W}_{18}$ precursor is about $2 \mathrm{~nm}$. [ $\mathrm{WO}_{6}$ ] and $\left[\mathrm{CoO}_{6}\right]$ octahedrons are connected by $\{\mathrm{Co}-\mathrm{O}-\mathrm{W}\}$ linkages, which favor the construction of rich interfaces. After calcination, only a slight aggregation of the neighboring particles exists due to the anchoring function of PEI. High-resolution TEM (HRTEM) images (Fig. 1d) show the lattice fringes with an interplanar distance of $0.196,0.209$, and $0.311 \mathrm{~nm}$, which correspond to the (112) lattice plane of CoP, (112) and (002) planes of WP, respectively. The detailed inverse fast Fourier transform (IFFT) spectra (Fig. 1e) further confirm the corresponding lattice distances of CoP and WP in the selected areas. More HRTEM images (Fig. S9) prove clear interfaces between CoP and WP in close contact. It should be noted that abundant interfaces are observed, which indicates the formation of multi-touch CoP-WP heterojunctions, enabling more accessible active sites. The uniform distribution of $\mathrm{W}, \mathrm{Co}, \mathrm{P}, \mathrm{N}$, and $\mathrm{C}$ elements in CoP-WP/ $\mathrm{rGO}$ is verified by $\mathrm{X}$-ray EDS elemental mapping graphs (Fig. 1f), demonstrating the successful fabrication of CoP-WP/ rGO, in which CoP and WP are firmly held together. The abundant multi-touch interfaces are considered as active sites in favor of HER. The nitrogen adsorption/desorption isotherm measurement was carried out to investigate the specific surface areas using the Brunauer-Emmett-Teller (BET) method. $\mathrm{N}_{2}$ adsorption/desorption isotherms (Fig. S10) of CoP-WP/rGO present typical type-IV isotherms with H3-type hysteresis loop, signifying the presence of mesoporous structure. The BET surface area is determined to be $112.1 \mathrm{~m}^{2} \mathrm{~g}^{-1}$ for CoP-WP/rGO, which is much larger than 79.2 and $4.3 \mathrm{~m}^{2} \mathrm{~g}^{-1}$ for rGO and CoPWP NPs. The far higher value of CoP-WP/rGO than that of CoP-WP NPs verifies the significant effect of $\mathrm{rGO}$ again. In addition, CoP-WP/rGO shows a higher BET surface area than rGO due to the "space separator" role of CoP-WP NPs in pre- venting rGO from stacking. The higher surface area is expected to expose more active sites. In the meantime, the porous structure is conducive to electrolyte penetration and charge transfer. The two points render CoP-WP/rGO superior thermodynamics and kinetics in the electrochemical process.

To gain further insight into the surface composition and valence states as well as the electron effect between WP and CoP, XPS was implemented. The survey spectra in Fig. 2a demonstrate the presence of $\mathrm{W}, \mathrm{P}, \mathrm{N}, \mathrm{C}$, and $\mathrm{O}$ elements in CoP-WP/ $\mathrm{rGO}$ and $\mathrm{WP} / \mathrm{rGO}$. The appearance of the $\mathrm{O} 1 \mathrm{~s}$ signal is caused by the inevitable surface oxidation of the materials when exposed to air [37]. For CoP-WP/rGO, a new peak assigned to Co $2 p$ emerges, meaning the successful incorporation of Co. As shown in Fig. $2 \mathrm{~b}$, the $\mathrm{W}$ 4f spectrum can be deconvoluted into two pairs of peaks. The sharp peaks at 32.0 and $34.1 \mathrm{eV}$ are characteristics of $\mathrm{W} 4 \mathrm{f}_{7 / 2}$ and $4 \mathrm{f}_{5 / 2}$, which can be assigned to the W-P bonds [38]. In addition, the other two peaks located at 36.1 and $38.2 \mathrm{eV}$ are associated with the $\mathrm{W}(\mathrm{VI})$ species due to the ineluctable surface oxidation [39]. Fig. 2c shows the high-resolution spectrum of Co $2 \mathrm{p}$. The Co $2 \mathrm{p}_{3 / 2}$ spectrum can be deconvolved into three main peaks. The binding energy of $778.5 \mathrm{eV}$ is ascribed to the Co-P, which agrees with the reported $\mathrm{Co}^{\delta+}$ signal from CoP in the literature [40]. The peak at $782.3 \mathrm{eV}$ implies the Co oxidation due to surface oxidation, accompanied by a shake-up satellite peak located at $786.8 \mathrm{eV}$ [41]. The presence of $\mathrm{W}-\mathrm{P}$ and $\mathrm{Co}-\mathrm{P}$ verifies the successful phosphorization of the $\mathrm{W}$ and Co elements. In the case of P $2 \mathrm{p}$ (Fig. 2d), the binding energies at 129.7 and $130.6 \mathrm{eV}$ are derived from $\mathrm{P} 2 \mathrm{p}_{3 / 2}$ and $\mathrm{P} 2 \mathrm{p}_{1 / 2}$, respectively, corresponding to metal-phosphide (M-P) bonds [42]. The binding energy at $132.7 \mathrm{eV}$ belonging to $\mathrm{P}-\mathrm{C}$ implies the presence of strong chemical interactions between rGO layer and CoP-WP [43]. The peak at $134.1 \mathrm{eV}$ (P-O) stems from the superficial $\mathrm{PO}_{4}{ }^{3-}$ [42]. The high-resolution $\mathrm{N}$ 1s spectrum (Fig. 2e) reveals the existence of metalnitrogen bond (M-N, 397.6 eV), pyridinic $\mathrm{N}(398.8 \mathrm{eV})$, pyrrolic $\mathrm{N}(399.6 \mathrm{eV})$, and graphitic $\mathrm{N}(401.0 \mathrm{eV})[42,44]$. As Fig. $2 \mathrm{f}$
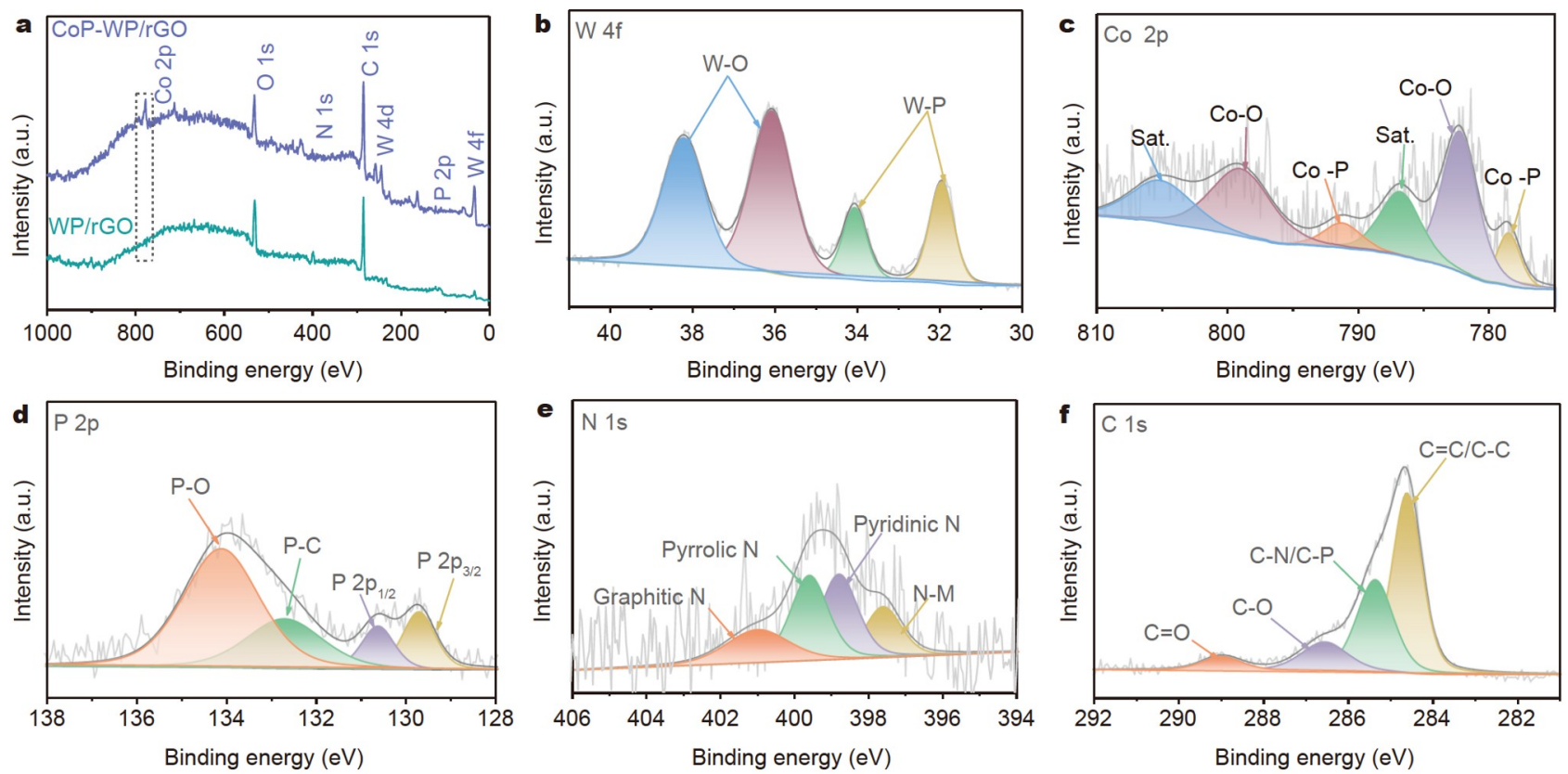

Figure 2 (a) XPS wide scan spectra of CoP-WP/rGO and WP/rGO, the high-resolution spectra of (b) W 4f, (c) Co 2p, (d) P 2p, (e) N 1s, and (f) C 1s in CoP$\mathrm{WP} / \mathrm{rGO}$. 
illustrates, a dominant peak of $\mathrm{C}-\mathrm{C} / \mathrm{C}=\mathrm{C}$ species $(284.6 \mathrm{eV})$ and three relatively weak peaks of $\mathrm{C}-\mathrm{N} / \mathrm{C}-\mathrm{P}(285.4 \mathrm{eV}), \mathrm{C}-\mathrm{O}$ $(286.6 \mathrm{eV})$, and $\mathrm{C}=\mathrm{O}(289.0 \mathrm{eV})$ suggest graphite-like $\mathrm{sp}^{2}$ bonded carbon accompanied by the successful doping of heteroatoms $(\mathrm{N}, \mathrm{P}, \mathrm{O})$ into $\mathrm{rGO}$ layer $[42,45]$. The high portion of $\mathrm{sp}^{2}$ carbon accounts for the enhanced electron conductivity. Meanwhile, heteroatoms doping could be conducive to optimizing hydrogen/hydroxyl adsorption energy [23,42]. The above analysis is suggestive of the successful fabrication of CoP-WP/ rGO. In comparison with the high-resolution $\mathrm{W}$ 4f spectrum of $\mathrm{WP} / \mathrm{rGO}$ sample (Fig. S11a), the $\mathrm{W} 4 \mathrm{f}_{7 / 2}(32.0 \mathrm{eV})$ and $4 \mathrm{f}_{5 / 2}$ $(34.1 \mathrm{eV})$ peaks assigned to $\mathrm{W}-\mathrm{P}$ of CoP-WP/rGO shift $0.4 \mathrm{eV}$ toward higher binding energies. As shown in Fig. S11b, no peak exists in the Co $2 \mathrm{p}$ zone of the $\mathrm{WP} / \mathrm{rGO}$ sample. The significant positive shift indicates electron redistribution between WP and $\mathrm{CoP}$ at the interfaces, in which CoP works as the electronattracting unit and draws the electrons from WP in CoP-WP/ rGO. The strong electronic interaction between CoP and WP in close contact can modulate the electronic structure of Co and W, improving the intrinsic electrochemical activity of catalysts [46].

\section{Electrochemical performance}

It is vital to exploit $\mathrm{pH}$-universal HER electrocatalysts with excellent catalytic activity for various renewable technologies in the future. Even though $\mathrm{Pt}$ is regarded as the benchmark HER electrocatalyst, performing effectively in acidic electrolyte, the HER activity in alkaline and neutral media drops 2-3 orders of magnitude because of the extra energy required for water dissociation [47]. Therefore, to meet the application requirements in different fields, developing $\mathrm{pH}$-universal efficient hydrogenevolving electrocatalysts is imperative.
The HER performance of CoP-WP/rGO was evaluated in $1.0 \mathrm{~mol} \mathrm{~L}^{-1} \mathrm{KOH}$ using a standard three-electrode setup with $\mathrm{Hg} / \mathrm{HgO}$ electrode as the reference electrode and graphite rod as the counter electrode. Meanwhile, $\mathrm{Pt} / \mathrm{C}, \mathrm{CoP} / \mathrm{rGO}, \mathrm{WP} / \mathrm{rGO}$, and CoP-WP NPs were used as the control samples. Fig. 3a shows the typical LSV curves of CoP-WP NPs, WP/rGO, CoP/ $\mathrm{rGO}, \mathrm{CoP}-\mathrm{WP} / \mathrm{rGO}$, and $\mathrm{Pt} / \mathrm{C}$ at a scan rate of $5 \mathrm{mV} \mathrm{s}^{-1}$. The commercial $\mathrm{Pt} / \mathrm{C}$ catalyst displays the anticipative outstanding catalytic activity. As observed, in comparison with $\mathrm{CoP} / \mathrm{rGO}$, $\mathrm{WP} / \mathrm{rGO}$, and CoP-WP NPs, CoP-WP/rGO gives the best HER catalytic activity, suggesting the heterostructure of CoP and WP, and the rGO integration in boosting the HER catalysis. To drive a current density of $10 \mathrm{~mA} \mathrm{~cm}{ }^{-2}, \mathrm{CoP}-\mathrm{WP} / \mathrm{rGO}$ requires a small overpotential $\left(\eta_{10}\right)$ of $96 \mathrm{mV}$, much lower than 123, 157, and $208 \mathrm{mV}$ for $\mathrm{CoP} / \mathrm{rGO}, \mathrm{WP} / \mathrm{rGO}$, and CoP-WP NPs, respectively. In consistent with the tendency of overpotentials at $10 \mathrm{~mA} \mathrm{~cm}$, the overpotentials of CoP-WP/rGO at 50,100 , and $200 \mathrm{~mA} \mathrm{~cm}^{-2}$ are also far below those of $\mathrm{CoP} / \mathrm{rGO}, \mathrm{WP} / \mathrm{rGO}$, and CoP-WP $\mathrm{NPs}$ at the same current densities (Fig. 3b). The CoP-WP/rGO demonstrates superior activity compared with the ever-reported WP-based HER catalysts (Table S1) [48-51], surpassing TMdoped WP electrocatalysts such as Co-WP $\left(\eta_{10}=119 \mathrm{mV}\right)$ and Mo-WP $\left(\eta_{10}=175 \mathrm{mV}\right)$ [48]. In one sense, the above phenomenon implies that constructing a heterostructure improves the catalytic activity more effectively than doping Co in WP. The HER performance of the CoP-WP/rGO is also one of the best among the previously reported $\mathrm{W}$-based and CoP-based catalysts (Tables S1 and S2) [48-55].

Tafel slopes were calculated (Fig. $3 \mathrm{c}$ ) to elucidate the catalytic kinetic mechanism. The Tafel slopes are 125, 94, 74, 62, and $36 \mathrm{mV} \mathrm{dec}{ }^{-1}$ for CoP-WP NPs, WP/rGO, CoP/rGO, CoP-WP/
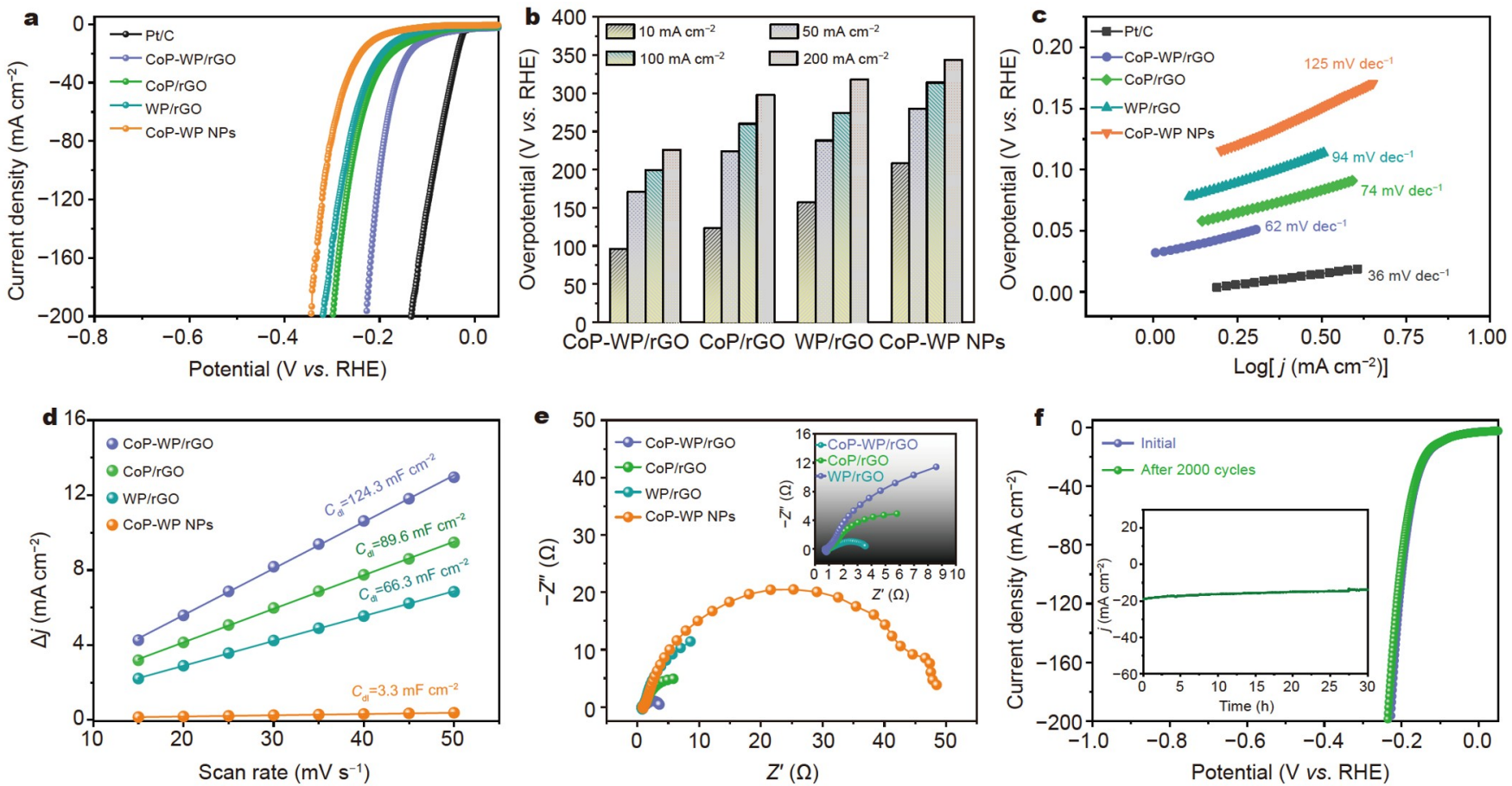

Figure 3 HER performance of the samples in $1 \mathrm{~mol} \mathrm{~L}^{-1} \mathrm{KOH}$ electrolyte. (a) Linear sweep polarization curves at a scan rate of $5 \mathrm{mV} \mathrm{s}{ }^{-1}$, (b) comparison of overpotentials at current densities of 10,50,100, and $200 \mathrm{~mA} \mathrm{~cm}^{-2}$ of various electrocatalysts, (c) the corresponding Tafel plots of the electrocatalysts in (a), (d) estimation of $C_{\mathrm{dl}}$ by plotting the current density variation $\left(\Delta j=\left(j_{\mathrm{a}}-j_{\mathrm{c}}\right) / 2\right)$, (e) Nyquist plots of different electrodes with a frequency range from 0.01 Hz to $100 \mathrm{kHz}$, (f) polarization curves for CoP-WP/rGO before and after 2000 cycles of CV test. Inset: the current-time (I-t) curve of CoP-WP/rGO under a static overpotential for $30 \mathrm{~h}$. 
rGO, and Pt/C, respectively. The Tafel slope of CoP-WP/rGO is smaller than the three counterparts, implying the HER kinetics on the CoP-WP/rGO catalyst is faster. The Tafel slope illustrates a Volmer-Heyrovsky reaction pathway on CoP-WP/rGO, signifying the electrochemical desorption is the rate-determining step [56]. The decreased Tafel slope after combining with rGO highlights the effective facilitation of the hydrogen evolution kinetics. To further explore the intrinsic property of the CoP$\mathrm{WP} / \mathrm{rGO}$, the exchange current density $\left(j_{0}\right)$ was probed by extrapolating the Tafel plot. As shown in Fig. S12, the $j_{0}$ of CoP$\mathrm{WP} / \mathrm{rGO}$ is $0.342 \mathrm{~mA} \mathrm{~cm}^{-2}$, which is much larger than those of $\mathrm{CoP} / \mathrm{rGO} \quad\left(0.215 \mathrm{~mA} \mathrm{~cm}^{-2}\right), \mathrm{WP} / \mathrm{rGO} \quad\left(0.157 \mathrm{~mA} \mathrm{~cm}^{-2}\right)$, and CoP-WP NPs catalysts $\left(0.135 \mathrm{~mA} \mathrm{~cm}^{-2}\right)$, indicating the superior $\mathrm{H}_{2}$ evolution activity of the CoP-WP/rGO.

The enhanced HER electrocatalytic activity of CoP-WP/rGO is related to the electrochemically active surface area, which is linearly proportional to the double-layer capacitance $\left(C_{\mathrm{dl}}\right)$. Therefore, $\mathrm{CV}$ tests were performed in a non-Faradic potential region of 0.10 to $0.20 \mathrm{~V}$ versus $\mathrm{RHE}$ at different scan rates (Fig. S13). The $C_{\mathrm{dl}}$ was estimated by plotting the current density variation at $0.15 \mathrm{~V}$ versus the scan rate. As displayed in Fig. 3d, the CoP-WP/rGO has a high $C_{\mathrm{dl}}$ value of $124.3 \mathrm{mF} \mathrm{cm}^{-2}$, higher than $\mathrm{CoP} / \mathrm{rGO}\left(89.6 \mathrm{mF} \mathrm{cm}^{-2}\right)$ and $\mathrm{WP} / \mathrm{rGO}\left(66.3 \mathrm{mF} \mathrm{cm}^{-2}\right)$. It is worth mentioning that the $C_{\mathrm{dl}}$ of $\mathrm{CoP}-\mathrm{WP} / \mathrm{rGO}$ is nearly 38 times as large as that of CoP-WP NPs $\left(3.3 \mathrm{mF} \mathrm{cm}^{-2}\right)$, which is closely in agreement with the $\mathrm{BET}$ surface area results. The high $C_{\mathrm{dl}}$ value of CoP-WP/rGO indicates CoP-WP/rGO can offer abundant catalytic active sites, giving rise to the best HER performance. The EIS test was performed to explore the HER reaction kinetics. Fig. 3e shows the Nyquist plots of the different electrodes. The CoP-WP/rGO Nyquist plot shows the smallest semicircle among all tested materials, which means CoP-WP/ rGO has the lowest charge transfer resistance $\left(R_{\mathrm{ct}}\right)$ at the electrode/electrolyte interface. The lowest $R_{\mathrm{ct}}$ value suggests the fastest charge transfer on the CoP-WP/rGO catalyst during the HER. The charge transfer ability enhancement of CoP-WP/rGO can be ascribed to incorporating high conductive rGO substrate. The durability of $\mathrm{CoP}-\mathrm{WP} / \mathrm{rGO}$ was investigated by the longterm $\mathrm{CV}$ cycles and chronoamperometric response test in $1.0 \mathrm{~mol} \mathrm{~L}^{-1} \mathrm{KOH}$. As shown in Fig. 3f, after $2000 \mathrm{CV}$ cycles, the polarization curve almost overlaps with the original curve, suggesting excellent stability. The time-dependent current density curve exhibits almost constant current density after $30 \mathrm{~h}$ (inset in Fig. 3f), further illustrating the superior durability. After the durability test, no apparent changes emerge in the XRD pattern and XPS spectra (Figs S14 and S15). The crystal structure and chemical state are held, implying exceptional electrochemistry stability of CoP-WP/rGO.

A series of contrast samples were fabricated by changing the phosphating temperature and mass ratio of $\mathrm{Co}_{8} \mathrm{~W}_{18}$ and $\mathrm{GO}$ to explore their influences on the HER activity (Table S3). Compared with CoP-WP/rGO-700 and CoP-WP/rGO-900, the CoP$\mathrm{WP} / \mathrm{rGO}$ catalyst (calcinated at $800^{\circ} \mathrm{C}$ ) exhibits the best HER activity with the smallest $\eta_{10}$ and Tafel slope (Fig. S16), demonstrating the appropriate phosphating temperature is an essential factor in HER activity. The primary reason is that phosphating temperature can affect the degree of crystallinity and the sizes of particles. As shown in Fig. S17, the peak intensity increases, and the peak width gradually narrows along with increasing phosphating temperature. Too high phosphating temperature results in an electrical conductivity decrease, ver- ified by the EIS test (Fig. S18). In further exploration, the HER performance of the relevant $\mathrm{CoP}-\mathrm{WP} / \mathrm{rGO}$ catalyst is also influenced by the mass ratio of $\mathrm{Co}_{8} \mathrm{~W}_{18}$ and GO. As displayed in Fig. S19, the peak at about $26.2^{\circ}$ assigned to the (002) facet of graphitic carbon becomes weak and disappears as the loading amount of $\mathrm{Co}_{8} \mathrm{~W}_{18}$ increases. Meanwhile, the intensities of other peaks, especially the one located at $31.6^{\circ}$, are enhanced gradually with the rise of the loading content. When the mass ratio of $\mathrm{Co}_{8} \mathrm{~W}_{18}$ and $\mathrm{GO}$ is $1.5, \mathrm{CoP}-\mathrm{WP} / \mathrm{rGO}$ catalyst shows the most excellent HER performance, given the lowest $\eta_{10}$ and smallest Tafel slope (Fig. S20). The EIS test shows that the loading content has an impact on the electrical conductivity (Fig. S21). The above results illustrate that the catalytic activity toward HER is closely correlated with suitable phosphating temperature and loading mass.

Developing acidic media HER electrocatalysts is also a significant and valuable subject since the acidic environment is conducive to HER. Therefore, the HER activity of the CoP-WP/ rGO sample was also investigated in $0.5 \mathrm{~mol} \mathrm{~L}^{-1} \mathrm{H}_{2} \mathrm{SO}_{4}$ electrolyte. As shown in Fig. 4a, commercial Pt/C possesses outstanding activity with low overpotentials, aligning closely with the literature [56]. Apart from $\mathrm{Pt} / \mathrm{C}$, the CoP-WP/rGO represents the smallest $\eta_{10}$ of $130 \mathrm{mV}$, while $\mathrm{CoP} / \mathrm{rGO}, \mathrm{WP} / \mathrm{rGO}$, and CoP-WP NPs need 159, 194, and $239 \mathrm{mV}$ to reach a current density of $10 \mathrm{~mA} \mathrm{~cm}^{-2}$, respectively (Fig. 4b). The Tafel slopes (Fig. 4c) of Pt/C, CoP-WP/rGO, CoP/rGO, WP/rGO, and CoPWP NPs are 37, 54, 62, 78, and $124 \mathrm{mV} \mathrm{dec}^{-1}$, respectively. The Tafel slope of CoP-WP/rGO is close to that of commercial Pt/C, indicating that $\mathrm{CoP}-\mathrm{WP} / \mathrm{rGO}$ undergoes a Volmer-Heyrovsky mechanism during the HER process. $j_{0}$ is another critical metric to evaluate the inherent HER electrocatalytic activity. CoP-WP/ rGO has the largest $j_{0}$ of $0.0383 \mathrm{~A} \mathrm{~cm}^{-2}$, which is higher than those of $\mathrm{CoP} / \mathrm{rGO} \quad\left(0.0319 \mathrm{~mA} \mathrm{~cm}^{-2}\right), \quad \mathrm{WP} / \mathrm{rGO}$ $\left(0.0207 \mathrm{~mA} \mathrm{~cm}^{-2}\right)$, and CoP-WP NPs $\left(0.0175 \mathrm{~mA} \mathrm{~cm}^{-2}\right)$, as shown in Fig. S22. The $C_{\mathrm{dl}}$ was calculated to explore the effective active surface area during the electrocatalytic process. The CV curves (Fig. S23) of different samples were tested at different rates from 10 to $50 \mathrm{mV} \mathrm{s}^{-1}$. The $C_{\mathrm{dl}}$ of CoP-WP/rGO (Fig. $4 \mathrm{~d}$ ) is $109.1 \mathrm{mF} \mathrm{cm}^{-2}$, which is far larger than that of $\mathrm{CoP} / \mathrm{rGO}$ (76.9 $\left.\mathrm{mF} \mathrm{cm}^{-2}\right), \mathrm{WP} / \mathrm{rGO}\left(62.4 \mathrm{mF} \mathrm{cm}^{-2}\right)$, and about two orders of magnitudes higher than that of CoP-WP NPs $\left(1.7 \mathrm{mF} \mathrm{cm}^{-2}\right)$. $\mathrm{CoP}-\mathrm{WP} / \mathrm{rGO}$ has the highest $C_{\mathrm{dl}}$ value, signifying the exposure of abundant active sites. As displayed in Fig. 4e, the Nyquist plot shows the smallest semicircle for CoP-WP/rGO, indicating that it holds a much smaller $R_{\mathrm{ct}}$, in contrast to the CoP/rGO, WP/ rGO, and CoP-WP NPs. The smallest $R_{\mathrm{ct}}$ endows CoP-WP/rGO with efficient electron transport and catalytic kinetics, giving rise to high activity and low Tafel slope. After 2000 cycles of the CV test, no apparent change can be observed (Fig. 4f), which shows the high stability of CoP-WP/rGO in corrosive acidic electrolyte. Besides, CoP-WP/rGO exhibits excellent stability with negligible degradation over $30 \mathrm{~h}$ operation (Fig. $4 \mathrm{f}$ inset). The CoP-WP/ rGO electrocatalyst possesses exceptional HER activity with a low overpotential, a small Tafel slope, a high exchange current density, and excellent stability in acidic electrolyte.

It is no wonder that HER electrocatalysts working in neutral or near-neutral electrolytes are of more practical significance given their potential application in seawater electrolysis and microbial electrolysis cell. In this regard, the HER performances in $1.0 \mathrm{~mol} \mathrm{~L}^{-1} \mathrm{PBS}$ electrolyte were further evaluated. As seen in Fig. 5a, except $\mathrm{Pt} / \mathrm{C}, \mathrm{CoP}-\mathrm{WP} / \mathrm{rGO}$ performs very well in the 

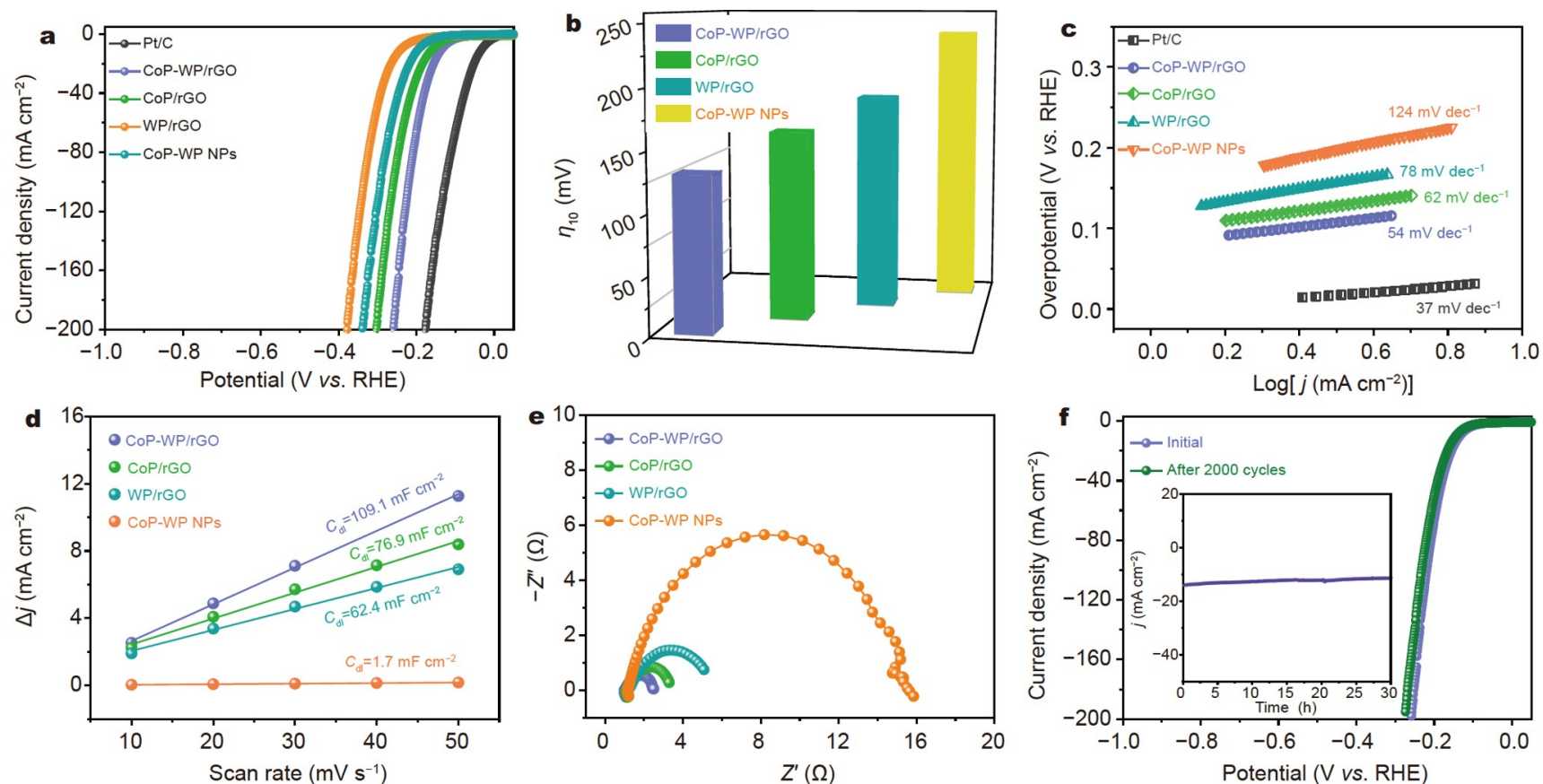

Figure 4 HER performance of the samples in $0.5 \mathrm{~mol} \mathrm{~L}^{-1} \mathrm{H}_{2} \mathrm{SO}_{4}$ electrolyte. (a) Linear sweep polarization curves at a scan rate of $5 \mathrm{mV} \mathrm{s}{ }^{-1}$, (b) the corresponding Tafel plots of the electrocatalysts in (a), (c) overpotentials at $10 \mathrm{~mA} \mathrm{~cm}{ }^{-2}$ of the electrocatalysts, (d) plots showing extraction of the double-layer capacitance $\left(C_{\mathrm{dl}}\right)$, (e) Nyquist plots of different electrodes with a frequency range from $0.01 \mathrm{~Hz}$ to $100 \mathrm{kHz}$, (f) polarization curves of CoP-WP/rGO before and after 2000 cycles of CV test. Inset: the $I-t$ curve of CoP-WP/rGO for $30 \mathrm{~h}$.
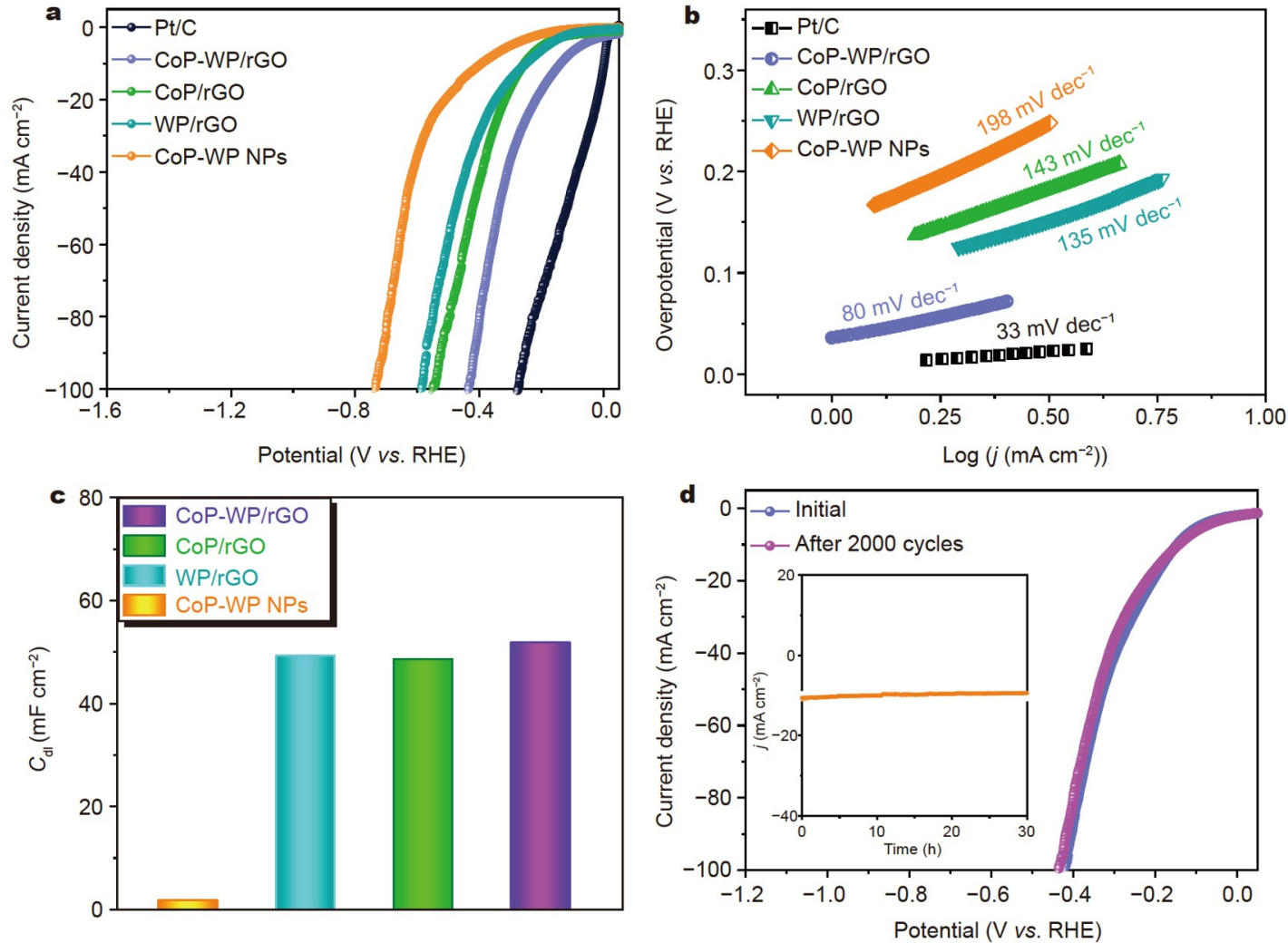

Figure 5 HER performance of the samples in $1.0 \mathrm{~mol} \mathrm{~L}^{-1} \mathrm{PBS}$ electrolyte. (a) Linear sweep polarization curves at a scan rate of $5 \mathrm{mV} \mathrm{s}{ }^{-1}$, (b) the corresponding Tafel plots of the electrocatalysts in (a), (c) $C_{\mathrm{dl}}$ values of different electrodes, (d) polarization curves for CoP-WP/rGO before and after 2000 cycles of CV test. Inset: the I- $t$ curve of CoP-WP/rGO under a static overpotential for $30 \mathrm{~h}$. 
neutral HER, with about $138 \mathrm{mV}$ to deliver $10 \mathrm{~mA} \mathrm{~cm}^{-2}$ current density, which is much lower than that of CoP/rGO $(254 \mathrm{mV})$, $\mathrm{WP} / \mathrm{rGO}(249 \mathrm{mV})$, and CoP-WP NPs $(392 \mathrm{mV})$. This confirms the vital function of heterojunction and hybridization with $\mathrm{rGO}$. The Tafel slope $\left(80 \mathrm{mV} \mathrm{dec}^{-1}\right)$ for CoP-WP/rGO is also lower than $143 \mathrm{mV} \mathrm{dec}^{-1}$ for $\mathrm{CoP} / \mathrm{rGO}, 135 \mathrm{mV} \mathrm{dec}^{-1}$ for $\mathrm{WP} / \mathrm{rGO}$, and $198 \mathrm{mV} \mathrm{dec}^{-1}$ for CoP-WP NPs (Fig. 5b). In this case, the exchange current densities of the above samples (Fig. S24) follow the same trend, $j_{0}\left(\mathrm{CoP}-\mathrm{WP} / \mathrm{rGO}, 0.387 \mathrm{~mA} \mathrm{~cm}^{-2}\right)>j_{0}(\mathrm{WP} /$ $\left.\mathrm{rGO}, 0.199 \mathrm{~mA} \mathrm{~cm}^{-2}\right)>j_{0}\left(\mathrm{CoP} / \mathrm{rGO}, 0.189 \mathrm{~mA} \mathrm{~cm}^{-2}\right)>j_{0}$ (CoP-WP NPs, $0.154 \mathrm{~mA} \mathrm{~cm}^{-2}$ ). The lowest Tafel slope and the largest $j_{0}$ indicate $\mathrm{CoP}-\mathrm{WP} / \mathrm{rGO}$ is equipped with the most efficient kinetics toward HER. In addition, EIS was tested to gain further insight into electrode kinetics. As shown in Fig. S25, $\mathrm{CoP}-\mathrm{WP} / \mathrm{rGO}$ possesses the smallest semicircle, suggesting the lowest charge transfer resistance and the fastest charge transfer. The charge transfer capacity of CoP-WP/rGO is far beyond that of CoP-WP NPs, mainly due to its high conductivity inherited from rGO, apart from the electronic interaction between $\mathrm{CoP}$, $\mathrm{WP}$, and rGO. Then, $C_{\mathrm{dl}}$ was used as the indicator to compare the electrochemical active surface areas. The $C_{\mathrm{dl}}$ of CoP-WP/ rGO is evaluated as $51.9 \mathrm{mF} \mathrm{cm}^{-2}$ (Fig. $5 \mathrm{c}$ and Fig. S26). The $C_{\mathrm{dl}}$ values of $\mathrm{CoP} / \mathrm{rGO}, \mathrm{WP} / \mathrm{rGO}$, and CoP-WP NPs are lower, i.e., 48.6, 49.3, and $1.8 \mathrm{mF} \mathrm{cm}^{-2}$, respectively. The highest $C_{\mathrm{dl}}$ indicates $\mathrm{CoP}-\mathrm{WP} / \mathrm{rGO}$ holds the most exposed active sites. Catalytic durability is also an essential factor for applications. As observed in Fig. 5d, the polarization curve presents negligible degradation after successive 2000 cycles of CV test. The CoP$\mathrm{WP} / \mathrm{rGO}$ maintains the initial catalytic activity after continuous $30 \mathrm{~h}$ in $1.0 \mathrm{~mol} \mathrm{~L}^{-1}$ PBS electrolyte.

Taking the characteristic structure and composition of CoP$\mathrm{WP} / \mathrm{rGO}$ as well as the performance differences between CoP$\mathrm{WP} / \mathrm{rGO}$ and the contrast samples into account, the excellent electrocatalytic activity of CoP-WP/rGO toward HER is stemmed from the following points. (1) The synergistic effect among $\mathrm{CoP}, \mathrm{WP}$, and rGO could modulate the electron density states to facilitate the adsorption and desorption of the active intermediates, thus boosting hydrogen evolution. (2) The introduction of rGO as carbon support could improve the electrical conductivity of the as-obtained material and offer a large specific surface area, which is essential to promote the HER. (3) The confinement effect of the rGO support could prevent the migration of the NPs, conducive to the uniform distribution of the two metal-phosphide NPs, leading to enhanced stability.

Density functional theory calculations were further used to explore the heterojunction effect on the electronic structure of electrocatalyst and the corresponding HER performance. The theoretical calculation details are described in the Supplementary information. Fig. 6a shows the geometric models of CoP, WP, and CoP-WP heterojunction. Generally, the hydrogen adsorption Gibbs free energy $\left(\Delta G_{\mathrm{H}^{*}}\right)$ is an indicator of HER activity. The closer the $\Delta G_{\mathrm{H}^{*}}$ value is to zero for HER catalysts, the better the kinetics. For instance, the standard Pt shows a moderate $\Delta G_{\mathrm{H}^{*}}$ about $-0.09 \mathrm{eV}$ [6]. Therefore, the $\mathrm{H}^{*}$ adsorption energies on CoP, WP, and CoP-WP heterojunction surfaces were calculated. As shown in Fig. $6 \mathrm{~b}$, the $\left|\Delta G_{\mathrm{H}^{*}}\right|$ values of the pristine $\mathrm{CoP}$ and $\mathrm{WP}$ are 0.250 and $1.029 \mathrm{eV}$, respectively. Contrastively, CoP-WP heterojunction exhibits a small $\left|\Delta G_{\mathrm{H}^{*}}\right|$ value of $0.177 \mathrm{eV}$, demonstrating a low energy barrier for $\mathrm{H}$ adsorption/desorption on CoP-WP heterojunction during the HER process. The lowest $\left|\Delta G_{\mathrm{H}^{*}}\right|$ value of CoP-WP heterojunc- tion indicates the heterointerfaces are conducive to optimizing $\mathrm{H}^{*}$ adsorption ability, causing the elevated HER activity. Additionally, Fig. $6 \mathrm{c}$ demonstrates the density of states (DOS) of CoP, WP, and CoP-WP heterojunction across the Fermi level, which indicates the metallic nature of the catalysts, facilitating rapid electron transfer for HER. Moreover, CoP-WP heterojunction holds higher DOS near the Fermi level than CoP and WP, implying that the charge carrier density of CoP-WP heterojunction increases. The relatively high conductivity of CoP-WP heterojunction greatly conduces to fast electron transport during the electrocatalytic process, which is consistent with the results from EIS tests. The electron density difference is introduced to investigate the electronic structure modulation by the heterointerfaces. The electron redistribution occurs at the interface, where the electrons transfer from WP to CoP, closely agreeing with the XPS results. It is beneficial to optimizing hydrogen adsorption free energy. The SKP test was implemented to estimate the work function (WF) values of the catalysts. As displayed in Fig. 6d and Fig. S27, the WF values of CoP-WP/rGO, $\mathrm{WP} / \mathrm{rGO}$, CoP/rGO, and CoP-WP NPs are 5.676, 5.751, 5.543, and $4.902 \mathrm{eV}$, respectively. The $\mathrm{WF}$ value of $\mathrm{CoP}-\mathrm{WP} / \mathrm{rGO}$ approaches that of $\mathrm{Pt}(5.680 \mathrm{eV})$ [42]. CoP-WP/rGO possesses exclusive ability to trap the electrons as $\mathrm{Pt}$, perhaps accounting for the boosted HER catalytic activity. After comparing the WF values of the above samples side-by-side, it turns out that both the formation of the heterojunctions and the coupling with rGO substrate tailor the electronic structure of the CoP-WP/rGO, generating active sites for HER.

$\mathrm{CoP}-\mathrm{WP} / \mathrm{rGO}$ is coupled with $\mathrm{NiFe}-\mathrm{LDH} / \mathrm{NF}$ to explore its practicability for overall water splitting. NiFe-LDH/NF is chosen given its remarkable OER activity $[57,58]$. For comparison, $\mathrm{Pt} / \mathrm{C} /$ $\mathrm{NF}$ and $\mathrm{RuO}_{2} / \mathrm{NF}$ are assembled into a two-electrode electrolyzer. As shown in Fig. 6e, the CoP-WP/rGO/NF $\mid$ NiFeLDH/NF electrolyzer shows remarkable activity for overall water splitting with a low cell voltage of $1.55 \mathrm{~V}$ to drive a current density of $10 \mathrm{~mA} \mathrm{~cm}^{-2}$, which is very close to $\mathrm{Pt} / \mathrm{C} / \mathrm{NF} \| \mathrm{RuO}_{2} / \mathrm{NF}$ electrolyzer. The $\mathrm{CoP}-\mathrm{WP} / \mathrm{rGO} / \mathrm{NF} \| \mathrm{NiFeLDH}-/ \mathrm{NF}$ at large current density displays higher catalytic performance $\left(\eta_{20}=1.60 \mathrm{~V}, \eta_{50}=\right.$ $1.72 \mathrm{~V})$ than $\mathrm{Pt} / \mathrm{C} / \mathrm{NF} \| \mathrm{RuO}_{2} / \mathrm{NF}\left(\eta_{20}=1.62 \mathrm{~V}, \eta_{50}=1.77 \mathrm{~V}\right)$ and other previously reported catalysts (Table S4). The electrolyzer can be driven by a solar cell with $1.554 \mathrm{~V}$ (Fig. 6e, inset). In addition, the chronoamperometric curve (Fig. 6f) shows negligible degradation after continuous $30 \mathrm{~h}$ operation, indicating the long-term stability of $\mathrm{CoP}-\mathrm{WP} / \mathrm{rGO} / \mathrm{NF} \| \mathrm{NiFeLDH} / \mathrm{NF}$. The excellent activity and durability endow it with practical application potential to convert low-voltage electricity into chemical energy.

\section{CONCLUSIONS}

In conclusion, we propose a powerful strategy to construct CoPWP heterojunctions anchored on $\mathrm{rGO}$ (CoP-WP/rGO) with multi-coupled interfaces by utilizing a POM-based polynuclear cobalt molecular cluster $\left(\mathrm{Co}_{8} \mathrm{~W}_{18}\right)$ as a precursor. The precise ratio of $\mathrm{CoP}$ to $\mathrm{WP}$ can be achieved through inheriting the metal atom ratio from $\mathrm{Co}_{8} \mathrm{~W}_{18}$. The $\mathrm{CoP}-\mathrm{WP} / \mathrm{rGO}$ improves $\mathrm{HER}$ performance with the low overpotentials and long durability in alkaline, acidic, and neutral electrolytes. The enhanced electrocatalytic performance can be ascribed to the abundant "multitouch" CoP-WP heterointerfaces, where electron redistribution occurs, leading to the optimized free energy of adsorbed hydrogen $\left(\Delta G_{\mathrm{H}^{*}}\right)$. This work offers a valuable reference for the 


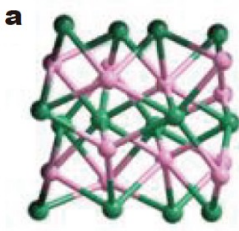

CoP

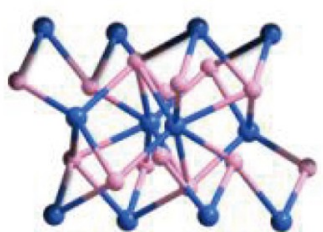

WP

Co atom $\odot$ atom $\mathrm{W}$ atom

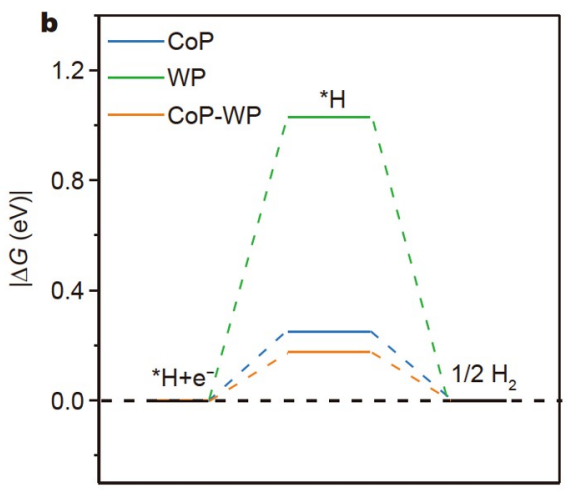

Reaction coordinate

c

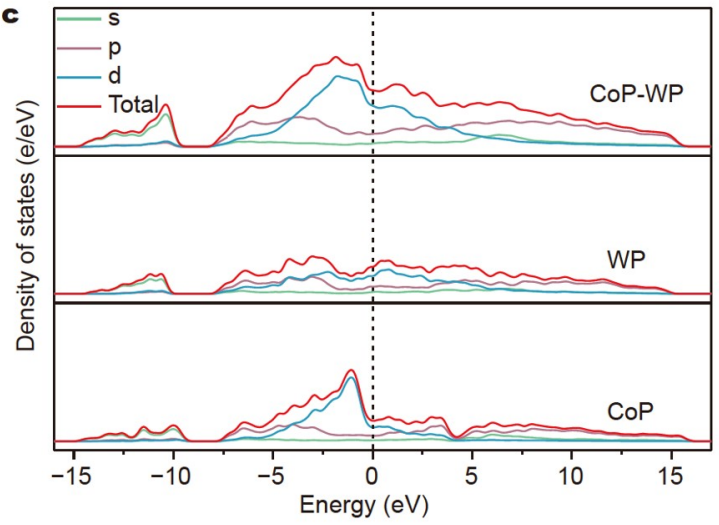

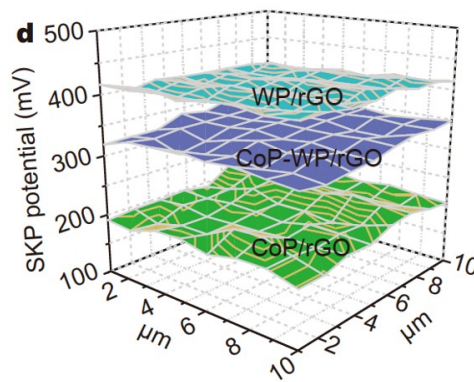
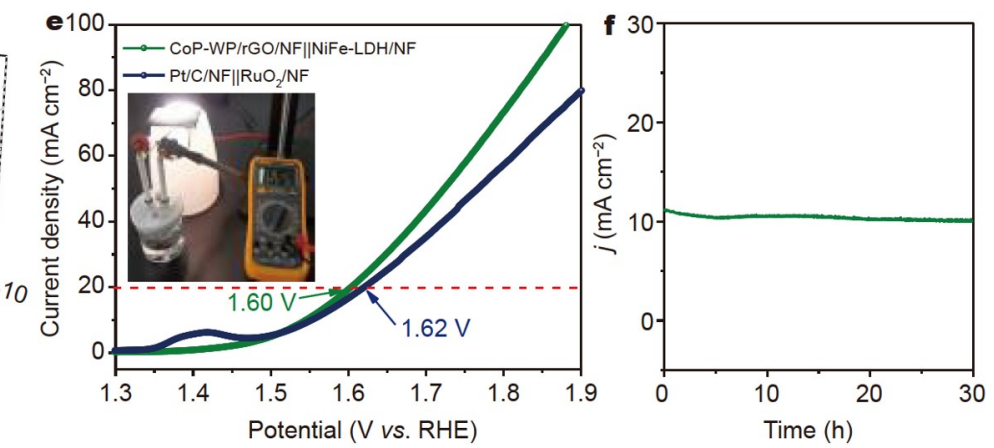

Figure 6 (a) Geometric models of CoP, WP, and CoP-WP heterojunction. (b) Free-energy diagram of $\left|\Delta G_{\mathrm{H}^{*}}\right|$; (c) DOS of CoP, WP, and CoP-WP heterojunction system. (d) The WF drawings of CoP, WP, and CoP-WP heterojunction. (e) Polarization curves for CoP-WP/rGO/NF $/ \mathrm{NiFeLDH} / \mathrm{NF}$ and Pt/ $\mathrm{C} / \mathrm{NF}|| \mathrm{RuO}_{2} / \mathrm{NF}$ in $1 \mathrm{~mol} \mathrm{~L}{ }^{-1} \mathrm{KOH}$. Inset: digital photograph of solar panel-assisted water splitting device. (f) $I-t$ curve of CoP-WP/rGO/NF $\mid \mathrm{NiFeLDH} / \mathrm{NF}$ for $30 \mathrm{~h}$.

fabrication of multi-interface contacted heterostructure catalysts for electrocatalysis.

Received 23 August 2021; accepted 5 November 2021; published online 5 January 2022

1 Kibsgaard J, Chorkendorff I. Considerations for the scaling-up of water splitting catalysts. Nat Energy, 2019, 4: 430-433

2 Garcés-Pineda FA, Blasco-Ahicart M, Nieto-Castro D, et al. Direct magnetic enhancement of electrocatalytic water oxidation in alkaline media. Nat Energy, 2019, 4: 519-525

3 Chen $\mathrm{H}$, Liang $\mathrm{X}$, Liu $\mathrm{Y}$, et al. Active site engineering in porous electrocatalysts. Adv Mater, 2020, 32: 2002435

4 Lei Z, Wang T, Zhao B, et al. Recent progress in electrocatalysts for acidic water oxidation. Adv Energy Mater, 2020, 10: 2000478

5 Zhu J, Hu L, Zhao P, et al. Recent advances in electrocatalytic hydrogen evolution using nanoparticles. Chem Rev, 2020, 120: 851-918

6 Fajín JLC, D. S. Cordeiro MN, Gomes JRB. Density functional theory study of the water dissociation on platinum surfaces: General trends. J Phys Chem A, 2014, 118: 5832-5840

$7 \mathrm{Xu} \mathrm{S}$, Zhao H, Li T, et al. Iron-based phosphides as electrocatalysts for the hydrogen evolution reaction: Recent advances and future prospects. J Mater Chem A, 2020, 8: 19729-19745
8 Zhao G, Rui K, Dou SX, et al. Heterostructures for electrochemical hydrogen evolution reaction: A review. Adv Funct Mater, 2018, 28 : 1803291

9 Yuan CZ, Hui KS, Yin $\mathrm{H}$, et al. Regulating intrinsic electronic structures of transition-metal-based catalysts and the potential applications for electrocatalytic water splitting. ACS Mater Lett, 2021, 3: 752-780

10 Su D, Zhang $\mathrm{X}, \mathrm{Wu} \mathrm{A}$, et al. $\mathrm{CoO}-\mathrm{Mo}_{2} \mathrm{~N}$ hollow heterostructure for high-efficiency electrocatalytic hydrogen evolution reaction. NPG Asia Mater, 2019, 11: 78-89

11 Dong X, Jiao Y, Yang G, et al. One-dimensional $\mathrm{Co}_{9} \mathrm{~S}_{8}-\mathrm{V}_{3} \mathrm{~S}_{4}$ heterojunctions as bifunctional electrocatalysts for highly efficient overall water splitting. Sci China Mater, 2021, 64: 1396-1407

12 Yang G, Jiao $\mathrm{Y}$, Yan $\mathrm{H}$, et al. Interfacial engineering of $\mathrm{MoO}_{2}-\mathrm{FeP}$ heterojunction for highly efficient hydrogen evolution coupled with biomass electrooxidation. Adv Mater, 2020, 32: 2000455

$13 \mathrm{Wu} \mathrm{A}$, Xie $\mathrm{Y}, \mathrm{Ma} \mathrm{H}$, et al. Integrating the active OER and HER components as the heterostructures for the efficient overall water splitting. Nano Energy, 2018, 44: 353-363

14 Xiao Y, Tian C, Tian M, et al. Cobalt-vanadium bimetal-based nanoplates for efficient overall water splitting. Sci China Mater, 2018, 61: 8090

15 Yan $\mathrm{H}, \mathrm{Xie} \mathrm{Y}, \mathrm{Wu} \mathrm{A}$, et al. Anion-modulated HER and OER activities of 3D Ni-V-based interstitial compound heterojunctions for high-effi- 
ciency and stable overall water splitting. Adv Mater, 2019, 31: 1901174

16 Jin S. Are metal chalcogenides, nitrides, and phosphides oxygen evolution catalysts or bifunctional catalysts? ACS Energy Lett, 2017, 2: 1937-1938

17 Kibsgaard J, Tsai C, Chan K, et al. Designing an improved transition metal phosphide catalyst for hydrogen evolution using experimental and theoretical trends. Energy Environ Sci, 2015, 8: 3022-3029

18 Shi Y, Li M, Yu Y, et al. Recent advances in nanostructured transition metal phosphides: Synthesis and energy-related applications. Energy Environ Sci, 2020, 13: 4564-4582

19 Tang YJ, Zhu HJ, Dong LZ, et al. Solid-phase hot-pressing of POMsZIFs precursor and derived phosphide for overall water splitting. Appl Catal B-Environ, 2019, 245: 528-535

20 Zhang B, Zheng X, Voznyy O, et al. Homogeneously dispersed multimetal oxygen-evolving catalysts. Science, 2016, 352: 333-337

$21 \mathrm{Wu}$ A, Gu Y, Yang B, et al. Porous cobalt/tungsten nitride polyhedra as efficient bifunctional electrocatalysts for overall water splitting. J Mater Chem A, 2020, 8: 22938-22946

22 Zheng J, Chen J, Xiao L, et al. In situ integrated $\mathrm{Co}_{3} \mathrm{~W}-\mathrm{WN}$ hybrid nanostructure as an efficient bifunctional electrocatalyst by accelerating water dissociation and enhancing oxygen evolution. ChemElectroChem, 2020, 7: 4971-4978

23 Weng B, Grice CR, Meng W, et al. Metal-organic framework-derived CoWP@C composite nanowire electrocatalyst for efficient water splitting. ACS Energy Lett, 2018, 3: 1434-1442

24 Zhang Y, Liu J, Li SL, et al. Polyoxometalate-based materials for sustainable and clean energy conversion and storage. EnergyChem, 2019, 1: 100021

25 Gong WP, Ke XF, Li ZP, et al. Adsorption of methylene blue by phosphomolybdiumtungstic acid decorated metal organic framework MOF-5. Chin J Appl Chem, 2016, 33: 1047-1055

26 Ma YY, Lang ZL, Yan LK, et al. Highly efficient hydrogen evolution triggered by a multi-interfacial Ni/WC hybrid electrocatalyst. Energy Environ Sci, 2018, 11: 2114-2123

27 Tang YJ, Zhang AM, Zhu HJ, et al. Polyoxometalate precursors for precisely controlled synthesis of bimetallic sulfide heterostructure through nucleation-doping competition. Nanoscale, 2018, 10: 84048412

28 Lisnard L, Mialane P, Dolbecq A, et al. Effect of cyanato, azido, carboxylato, and carbonato ligands on the formation of cobalt(II) polyoxometalates: Characterization, magnetic, and electrochemical studies of multinuclear cobalt clusters. Chem Eur J, 2007, 13: 3525-3536

29 Wei J, Feng Y, Zhou P, et al. A bioinspired molecular polyoxometalate catalyst with two cobalt(II) oxide cores for photocatalytic water oxidation. ChemSusChem, 2015, 8: 2630-2634

30 Yan H, Tian C, Sun L, et al. Small-sized and high-dispersed WN from $\left[\mathrm{SiO}_{4}\left(\mathrm{~W}_{3} \mathrm{O}_{9}\right)_{4}\right]^{4-}$ clusters loading on GO-derived graphene as promising carriers for methanol electro-oxidation. Energy Environ Sci, 2014, 7: 1939-1949

31 Yan H, Tian C, Wang L, et al. Phosphorus-modified tungsten nitride/ reduced graphene oxide as a high-performance, non-noble-metal electrocatalyst for the hydrogen evolution reaction. Angew Chem Int Ed, 2015, 54: 6325-6329

32 Yan $\mathrm{H}$, Xie $\mathrm{Y}$, Jiao $\mathrm{Y}$, et al. Holey reduced graphene oxide coupled with an $\mathrm{Mo}_{2} \mathrm{~N}-\mathrm{Mo}_{2} \mathrm{C}$ heterojunction for efficient hydrogen evolution. Adv Mater, 2018, 30: 1704156

33 Gumerova NI, Rompel A. Polyoxometalates in solution: Speciation under spotlight. Chem Soc Rev, 2020, 49: 7568-7601

34 Wang $\mathrm{H}$, Liu X, Niu P, et al. Porous two-dimensional materials for photocatalytic and electrocatalytic applications. Matter, 2020, 2: 13771413

35 Jiao Y, Zheng Y, Davey K, et al. Activity origin and catalyst design principles for electrocatalytic hydrogen evolution on heteroatom-doped graphene. Nat Energy, 2016, 1: 1-9

36 Qu K, Zheng Y, Zhang X, et al. Promotion of electrocatalytic hydrogen evolution reaction on nitrogen-doped carbon nanosheets with secondary heteroatoms. ACS Nano, 2017, 11: 7293-7300

37 He C, Bo T, Wang B, et al. RGO induced one-dimensional bimetallic carbide nanorods: An efficient and $\mathrm{pH}$-universal hydrogen evolution reaction electrocatalyst. Nano Energy, 2019, 62: 85-93

$38 \mathrm{Wu} \mathrm{L}, \mathrm{Pu} \mathrm{Z}, \mathrm{Tu} \mathrm{Z}$, et al. Integrated design and construction of WP/W nanorod array electrodes toward efficient hydrogen evolution reaction. Chem Eng J, 2017, 327: 705-712

39 Li F, Wang C, Han X, et al. Confinement effect of mesopores: In situ synthesis of cationic tungsten-vacancies for a highly ordered mesoporous tungsten phosphide electrocatalyst. ACS Appl Mater Interfaces, 2020, 12: 22741-22750

40 Yang L, Liu R, Jiao L. Electronic redistribution: Construction and modulation of interface engineering on $\mathrm{CoP}$ for enhancing overall water splitting. Adv Funct Mater, 2020, 30: 1909618

41 Jin J, Cai W, Cai J, et al. MOF-derived hierarchical CoP nanoflakes anchored on vertically erected graphene scaffolds as self-supported and flexible hosts for lithium-sulfur batteries. J Mater Chem A, 2020, 8: 3027-3034

42 Jiao Y, Yan H, Wang R, et al. Porous plate-like MoP assembly as an efficient $\mathrm{pH}$-universal hydrogen evolution electrocatalyst. ACS Appl Mater Interfaces, 2020, 12: 49596-49606

43 Wu J, Wang D, Wan S, et al. An efficient cobalt phosphide electrocatalyst derived from cobalt phosphonate complex for all-pH hydrogen evolution reaction and overall water splitting in alkaline solution. Small, 2020, 16: 1900550

44 Ji L, Wang J, Teng X, et al. N,P-doped molybdenum carbide nanofibers for efficient hydrogen production. ACS Appl Mater Interfaces, 2018, 10: $14632-14640$

45 Yan $\mathrm{H}$, Jiao $\mathrm{Y}$, Wu A, et al. Cluster-like molybdenum phosphide anchored on reduced graphene oxide for efficient hydrogen evolution over a broad $\mathrm{pH}$ range. Chem Commun, 2016, 52: 9530-9533

46 Huang $\mathrm{X}, \mathrm{Xu} \mathrm{X}$, Luan $\mathrm{X}$, et al. CoP nanowires coupled with CoMoP nanosheets as a highly efficient cooperative catalyst for hydrogen evolution reaction. Nano Energy, 2020, 68: 104332

47 Dinh CT, Jain A, de Arquer FPG, et al. Multi-site electrocatalysts for hydrogen evolution in neutral media by destabilization of water molecules. Nat Energy, 2019, 4: 107-114

48 Wang J, Chang K, Sun Z, et al. A combined experimental and theoretical study of the accelerated hydrogen evolution kinetics over wide $\mathrm{pH}$ range on porous transition metal doped tungsten phosphide electrocatalysts. Appl Catal B-Environ, 2019, 251: 162-167

49 Pi M, Wu T, Guo W, et al. Phase-controlled synthesis of polymorphic tungsten diphosphide with hybridization of monoclinic and orthorhombic phases as a novel electrocatalyst for efficient hydrogen evolution. J Power Sources, 2017, 349: 138-143

$50 \mathrm{Pu} \mathrm{Z}$, Liu Q, Asiri AM, et al. Tungsten phosphide nanorod arrays directly grown on carbon cloth: A highly efficient and stable hydrogen evolution cathode at all $\mathrm{pH}$ values. ACS Appl Mater Interfaces, 2014, 6: 21874-21879

51 Tong $\mathrm{R}, \mathrm{Qu} \mathrm{Y}$, Zhu Q, et al. Combined experimental and theoretical assessment of $\mathrm{WX}_{y}(\mathrm{X}=\mathrm{C}, \mathrm{N}, \mathrm{S}, \mathrm{P})$ for hydrogen evolution reaction. ACS Appl Energy Mater, 2020, 3: 1082-1088

52 Wang X, Chen Y, Yu B, et al. Hierarchically porous W-doped CoP nanoflake arrays as highly efficient and stable electrocatalyst for $\mathrm{pH}$ universal hydrogen evolution. Small, 2019, 15: 1902613

53 Wang L, Li Z, Wang K, et al. Tuning d-band center of tungsten carbide via Mo doping for efficient hydrogen evolution and $\mathrm{Zn}-\mathrm{H}_{2} \mathrm{O}$ cell over a wide $\mathrm{pH}$ range. Nano Energy, 2020, 74: 104850-104858

54 Liu T, Liu D, Qu F, et al. Enhanced electrocatalysis for energy-efficient hydrogen production over $\mathrm{CoP}$ catalyst with nonelectroactive $\mathrm{Zn}$ as a promoter. Adv Energy Mater, 2017, 7: 1700020

55 Fan K, Zou H, Dharanipragada NVRA, et al. Surface and bulk reconstruction of $\mathrm{CoW}$ sulfides during $\mathrm{pH}$-universal electrocatalytic hydrogen evolution. J Mater Chem A, 2021, 9: 11359-11369

$56 \mathrm{Gu} \mathrm{Y,} \mathrm{Wu} \mathrm{A,} \mathrm{Jiao} \mathrm{Y,} \mathrm{et} \mathrm{al.} \mathrm{Two-dimensional} \mathrm{porous} \mathrm{molybdenum}$ phosphide/nitride heterojunction nanosheets for $\mathrm{pH}$-universal hydrogen evolution reaction. Angew Chem Int Ed, 2021, 60: 6673-6681

57 Wang $\mathrm{H}$, Zhu S, Deng J, et al. Transition metal carbides in electrocatalytic oxygen evolution reaction. Chin Chem Lett, 2021, 32: 291-298

$58 \mathrm{Wu} \mathrm{A}, \mathrm{Gu} \mathrm{Y}, \mathrm{Xie} \mathrm{Y}$, et al. Effective electrocatalytic hydrogen evolution in neutral medium based on $2 \mathrm{D} \mathrm{MoP} / \mathrm{MoS}_{2}$ heterostructure nanosheets. ACS Appl Mater Interfaces, 2019, 11: 25986-25995 
Acknowledgements This work was financially supported by the National Key R\&D Program of China (2018YFB1502401), the National Natural Science Foundation of China (91961111, 22171074, 21601055, U20A20250, 21805073, and 22005161), the Natural Science Foundation of Heilongjiang Province (ZD2021B003), China Postdoctoral Science Foundation (2017M611406), the Postdoctoral Science Foundation of Heilongjiang Province (LBH-Z16175), and the Scientific Research Funds of University Affiliated to Heilongjiang Province (KJCX201913).

Author contributions Fu H, Tian C, and Jiao Y conceived the idea. Jiao Y, Yan $\mathrm{H}$, and Wang $\mathrm{X}$ designed the experiments, collected and analyzed the data. Wang D, Wang R, Xu S, and Jiang L assisted with the experiments and characterizations. Xie $\mathrm{Y}$ and $\mathrm{Wu} \mathrm{A}$ assisted with theoretical calculations and analyzed the data. Fu H, Tian C and Jiao Y co-wrote the manuscript. All authors discussed the results and commented on the manuscript.

Conflict of interest The authors declare that they have no conflict of interest.

Supplementary information Experimental details and supporting data are available in the online version of the paper.

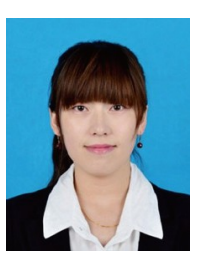

Yanqing Jiao received her BSc degree in 2010 and $\mathrm{PhD}$ degree in 2015 from the Northeast Normal University under the guidance of Prof. Zhongmin Su. Then she served as a lecturer at Heilongjiang University and conducted postdoctoral research with Prof. Honggang Fu. She has been an associate professor since 2017. Her research interests focus on synthesizing polyoxometalate-based composite materials and polyoxometalate-derived materials for energy storage and conversion.

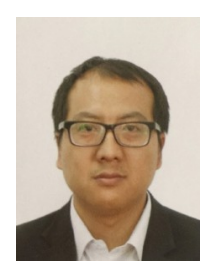

Chungui Tian received his BSc degree in 1997 from Inner Mongolia University for Nationalities. In 2004 and 2007, he received his MSc and $\mathrm{PhD}$ degrees from the Northeast Normal University under the guidance of Prof. Enbo Wang. Then, he joined Heilongjiang University as a lecturer. He became an assistant professor and full professor in 2009 and 2014, respectively. His interests focus on the synthesis and electrocatalytic application of W (Mo, V)based nanomaterials.

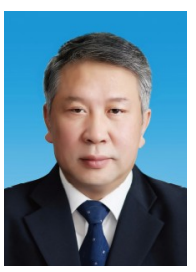

Honggang Fu received his BSc degree in 1984 and MSc degree in 1987 from Jilin University, China. He joined Heilongjiang University as an assistant professor in 1988. In 1999, he received his $\mathrm{PhD}$ degree from Harbin Institute of Technology, China. He became a full professor in 2000. Currently, he is a Cheung Kong Scholar Professor. His interests focus on oxide-based nanomaterials for solar energy conversion and photocatalysis, carbon-based nanomaterials for energy conversion and storage, and electrocatalysis.

\section{具有多触点界面的CoP-WP/rGO异质结助力宽 $\mathrm{pH}$ 析氢}

焦艳清 ${ }^{1}$, 间海静 ${ }^{1}$, 王东旭 ${ }^{1}$, 王秀文 ${ }^{2}$, 许思薇 ${ }^{1}$, 谢颖 ${ }^{1}$, 吴爱平 ${ }^{1}$, 姜莉 ${ }^{1}$, 田春贵 ${ }^{*}$, 王瑞红 ${ }^{1}$, 付宏刚 ${ }^{*}$

摘要 界面工程是一种通过调整电子结构提高催化活性的有效手段. 然而, 构建具有紧密接触界面的异质结仍然面临巨大的挑战. 本研究工 作中，我们引入具有确定结构的多酸基多核钴分子团簇 $\mathrm{Co}_{8} \mathrm{~W}_{18}$ 作为前 驱体，构建了紧密接触的多重界面耦合的CoP-WP异质结. 通过在氧化 石墨烯上生长 $\mathrm{Co}_{8} \mathrm{~W}_{18}$, 磷化处理后获得了针定在还原氧化石墨烯上的 CoP-WP异质结 $(\mathrm{CoP}-\mathrm{WP} / \mathrm{rGO}) . \mathrm{Co}_{8} \mathrm{~W}_{18}$ 中固有的 $\{\mathrm{Co}-\mathrm{O}-\mathrm{W}\}$ 配位模式 有利于形成紧密接触的界面. X射线光电子能谱分析和理论计算证实了 CoP-WP异质结中丰富的紧密接触界面促进了电子从 WP向 $\mathrm{CoP}$ 的转 移, 从而调节了界面电子结构, 优化了氢吸附自由能 $\left(\Delta G_{\mathrm{H}^{*}}\right)$. 与氧化石 墨的复合使得 $\mathrm{CoP}-\mathrm{WP} / \mathrm{rGO}$ 具有大的表面积和高的电导性, 有利于物 质传输和电荷转移. 因此, CoP-WP/rGO在碱性、酸性和中性介质中皆 表现出显著增强的HER活性, 在 $10 \mathrm{~mA} \mathrm{~cm} \mathrm{~cm}^{-2}$ 下过电位分别为 $96 、 130$ 和 $138 \mathrm{mV}$. 这项工作为设计具有多触点界面的异质结材料用作低成本和 高效HER电催化剂提供了一种新策略. 